\title{
Gut microbiota of obese and diabetic Thai subjects and interplay with dietary habits and blood profiles
}

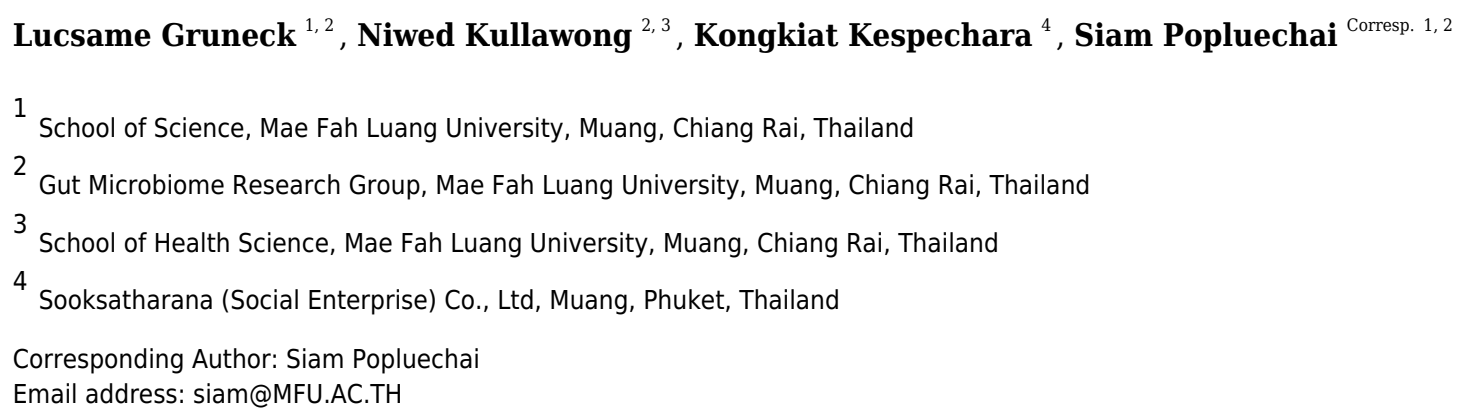

Obesity and type 2 diabetes mellitus (T2DM) have become major public health issues globally. Recent research indicates that intestinal microbiota play roles in metabolic disorders. Though there are numerous studies focusing on gut microbiota of health and obesity states, those are primarily focused on western countries. Comparatively only a few investigations exist on gut microbiota of people from Asian countries. In this study, the fecal microbiota of 30 adult volunteers living in Chiang Rai Province, Thailand were examined using next-generation sequencing (NGS) in association with blood profiles and dietary habits. Subjects were categorized by body mass index (BMI) and health status as follows; lean $(\mathrm{L})=8$, overweight $(\mathrm{OV})=8$, obese $(\mathrm{OB})=7$ and diagnosed $\mathrm{T} 2 \mathrm{DM}=7$. Members of T2DM group showed differences in dietary consumption and fasting glucose level compared to BMI groups. A low level of high-density cholesterol (HDL) was observed in the OB group. Principal coordinate analysis (PCOA) revealed that microbial communities of T2DM subjects were clearly distinct from those of OB. An analogous pattern was additionally illustrated by multiple factor analysis (MFA) based on dietary habits, blood profiles, and fecal gut microbiota in BMI and T2DM groups. In all four groups, Bacteroidetes and Firmicutes were the predominant phyla. Abundance of Faecalibacterium prausnitzii, a butyrate-producing bacterium, was significantly higher in OB than that in other groups. This study is the first to examine the gut microbiota of adult Thais in association with dietary intake and blood profiles and will provide the platform for future investigations. 


\section{Gut microbiota of obese and diabetic Thai subjects}

\section{2 and interplay with dietary habits and blood profiles}

3

4 Lucsame Gruneck ${ }^{1}$, Niwed Kullawong ${ }^{2,3}$, Kongkiat Kespechara ${ }^{4}$, and Siam Popluechai ${ }^{1,3}$ 5

Corresponding Author:

Siam Popluechai ${ }^{1,3}$

${ }^{1}$ School of Science, Mae Fah Luang University, Chiang Rai, 57100, Thailand

${ }^{3}$ Gut Microbiome Research Group, Mae Fah Luang University, Muang, Chiang Rai, Thailand

Email address: siam@mfu.ac.th

\section{Abstract}

Obesity and type 2 diabetes mellitus (T2DM) have become major public health issues globally. Recent research indicates that intestinal microbiota play roles in metabolic disorders. Though there are numerous studies focusing on gut microbiota of health and obesity states, those are primarily focused on western countries. Comparatively only a few investigations exist on gut microbiota of people from Asian countries. In this study, the fecal microbiota of 30 adult volunteers living in Chiang Rai Province, Thailand were examined using next-generation sequencing (NGS) in association with blood profiles and dietary habits. Subjects were categorized by body mass index (BMI) and health status as follows; lean (L) $=8$, overweight $(\mathrm{OV})=8$, obese $(\mathrm{OB})=7$ and diagnosed $\mathrm{T} 2 \mathrm{DM}=7$. Members of T2DM group showed differences in dietary consumption and fasting glucose level compared to BMI groups. A low level of high-density cholesterol (HDL) was observed in the OB group. Principal coordinate analysis (PCoA) revealed that microbial communities of T2DM subjects were clearly distinct 
31 from those of OB. An analogous pattern was additionally illustrated by multiple factor analysis

32 (MFA) based on dietary habits, blood profiles, and fecal gut microbiota in BMI and T2DM

33 groups. In all four groups, Bacteroidetes and Firmicutes were the predominant phyla. Abundance

34 of Faecalibacterium prausnitzii, a butyrate-producing bacterium, was significantly higher in OB

35 than that in other groups. This study is the first to examine the gut microbiota of adult Thais in

36 association with dietary intake and blood profiles and will provide the platform for future

37 investigations.

38

\section{Introduction}

40

41

42

43

44

45

46

47

48

49

50

51

52

53

54

55

56

57

58

59

Over the past decades, obesity has been recognized as a global epidemic that threatens quality and length of life. Obesity has also been recognized as a risk factor for developing noncommunicable diseases (NCDs) including cardiovascular diseases, cancers, diabetes and lung diseases (Caballero, 2007; Misra \& Khurana, 2011; Webber et al., 2012). The prevalence of obesity is increasing globally in populations living in both developed and developing countries. However, the trends in obesity vary across continents with respect to economic progress (from high- to low-income countries) (Jaacks et al., 2019). Inequitable income reflecting an individual's socioeconomic status seems to be one of the major factors that drive disparities in lifestyle-related health, particularly dietary behavior. In high-income countries (e.g. Western Europe and the United States), fresh foods are less affordable compared to processed foods among people with lower wages, which is a contributing factor to the increased prevalence of obesity (Drewnowski, 2009; Harrison \& Taren, 2018). The inverse correlation pattern between obesity and rate of income have been reported repeatedly in low-income and middle-income countries (Wang, 2001; Swinburn et al., 2011; Pampel, Denney \& Krueger, 2012; Harrison \& Taren, 2018). A dietary habit has been shifted among middle-income countries at a brisk pace. Traditional diet is rapidly being replaced by consumption of processed foods in parallel with increasing urbanization. Exposure to high-fat diets in relation to socioeconomic status revealed that urban children tended to become more obese than children living in rural environments (Kisuse et al., 2018b), an observation matched in urban workers (Xanthos, 2015). These patterns of dietary transition regarding convergence to obesogenic diets, which are energy-dense lead to 
60

61

62

63

64

65

66

67

68

69

70

71

72

73

74

75

76

77

78

79

80

81

82

83

84

85

86

87

88

89

90

obesity-related complications. The association of urbanization with obesity may thereby increase the burden of NCDs among populations (Low, 2016).

Body mass index (BMI) is widely used to assess health status based on weight and height. In general, higher BMI (overweight and/or obesity) is an indicator of increased risk of developing a range of conditions, including metabolic disorders, such as type 2 diabetes mellitus (T2DM) (Bays, Chapman \& Grandy, 2007; Han \& Boyko, 2018). Weight fluctuation is commonly associated with dietary consumption, and increasing food intake overtime, can lead to gaining weight. Westernized diets, which have high content of fats, sugars, and sodium, but are deficient in fibre, increase risk of obesity along with its comorbidities including T2DM, heart disease, and cancer (Mozaffarian et al., 2011; Manzel et al., 2014; Kopp, 2019). A strong relationship between BMI and T2DM has also been reported; the chance of developing T2DM increases in parallel with increasing BMI (Bays, Chapman \& Grandy, 2007; Ganz et al., 2014; Al-Goblan, Al-Alfi \& Khan, 2014; Gray et al., 2015). Currently, the interplay between BMI and microbes is a primary focus of research in determining host health traits.

The human gut harbors a large population of microorganisms, the gut microbiota, which exert a notable influence on the host in modulating energy balance (host metabolism and energy uptake). Numerous studies have suggested that bacteria residing within the human digestive tract are associated with health and disease states, and accordingly, they are involved in various host functions such as metabolism and immune system (Macpherson \& Harris, 2004; Sekirov et al., 2010; Tremaroli \& Bäckhed, 2012; Nicholson et al., 2012; Bull \& Plummer, 2014; Leung et al., 2016; Tang \& Hazen, 2016). Despite being abundant, an imbalance or disruption of the human gut flora can have a significant impact on disease susceptibility or occurrence (Manichanh et al., 2006; Clemente et al., 2012; Carding et al., 2015; Zhang et al., 2015b; Belizário \& Faintuch, 2018). Among the commonly and consistently reported findings, the genera of Bifidobacterium, Bacteroides, Faecalibacterium, Akkermansia and Roseburia have been negatively associated with T2DM, while the genera of Ruminococcus, Fusobacterium, and Blautia were positively associated with T2DM (Gurung et al., 2020). Several studies have also demonstrated the crucial role of dysbiosis of intestinal microbiota in correlation with NCDs. Recent evidence suggests that alteration of the gut microbial composition may predispose the host to obesity and diabetes (Bäckhed et al., 2005; Hur \& Lee, 2015; Serino et al., 2017). Evidence from mice and human studies have suggested that dysbiosis increases energy extraction from diet and enhances host 
91 energy harvest. Dysbiosis also induces obesity-associated inflammation in the host. The 92 complexity of bacterial communities is significantly reduced in obese individuals (Le Chatelier 93 et al., 2013). Restoring the lost complexity has been found to reduce metabolic disorders in 94 animals (Yin et al., 2010; Gauffin Cano et al., 2012; Everard et al., 2013; Bubnov et al., 2017), 95 which diets are considered as one of the major factors that contribute to the gut microbial 96 community (Rinninella et al., 2019).

Diet is one of the most prominent external factors that does not only affect composition and 98 abundance of gut microbiota, but also overall health. A relationship between diet and gut microbiota composition has been previously documented, whereby changes in gut microbial communities are influenced by variations in dietary components (Flint et al., 2012; David et al., 2014; Xu \& Knight, 2015). Thus, the response of microbiome to diet potentially contributes to

102

103

104 105

106

107 108

109

110

111

112

113

114

115

116

117

118 119 health status (Riaz Rajoka et al., 2017; Hughes et al., 2019). Thailand is used to be seen as a "lean nation". During the last decade, the diet of Thai people has been changing and becoming more westernized due to economic development (upgraded to a developing upper-middle-income country (The World Bank, 2011), higher income and globalization. These foods have a high calorie but low nutritional content and their excessive consumption has been linked to obesity. The contemporary prevalence of overweight and obesity in Thai adults is $40.9 \%$ (Jitnarin et al., 2011). Moreover, NCDs cause $71 \%$ of total deaths in Thailand (WHO, 2011). Although the microbiota patterns of obese adult Asian populations from some Asian countries such as China, India, and Japan (Kasai et al., 2015; Zhang et al., 2015a; Ahmad et al., 2019) are available, similar information on Thai gut microbiota is still limited. Given the unique culture and gastronomical lifestyle of Thailand, the present study aimed to (1) establish gut microbiota baselines of lean, overweight, obese, and T2DM in Thai populations and (2) explore associations of specific components of the gut microbiota with dietary habits and blood profiles in these populations.

\section{Materials \& Methods}

\section{Ethics Statement}

This study was approved by the Ethics Committee of Mae Fah Luang University (Ethics license: REH60075). The subjects were informed about the scope of the research project a day before 
120 participation using Thai-version information sheets. Written informed consents were obtained

121 from all participants before sample and questionnaire collections.

\section{Study subjects}

123 The study included 30 subjects from Chiang Rai province located in Northern Thailand, which 124 were considered to be representative of Thai population. Subject recruitment was conducted by 125 voluntary participation through community clinics in the province and was carried out in July 126 2017. Subjects were divided into two major groups including diabetics (T2DM) and non127 diabetics. Of these, seven subjects were placed in the T2DM group based on their morning 128 fasting blood sugar level (cutoff level of $>126 \mathrm{mg} / \mathrm{dL}$ ) (Reinauer H et al., 2003) and irrespective 129 of BMI. Twenty-three (non-diabetic) subjects were classified according to BMI using the criteria 130 set by the World Health Organization Western Pacific Region (WHO, 2004), as follows: 131 underweight $(\mathrm{BMI}<18.5)$, normal or lean $(18.5 \leq \mathrm{BMI}<24.9)$, overweight $(25.0 \leq \mathrm{BMI}<$ 132 29.9), and obese (BMI $\geq 30)$. Voluntary samples were taken from each group to meet a quota as 133 follows: seven for T2DM (female $(n=6)$, male $(n=1))$; eight for lean (female $(n=6)$, male $(n=1))$, 134 for overweight 8 (female $(n=6)$, male $(n=1))$ for overweight, and seven for obese (female $(n=3)$, 135 male ( $\mathrm{n}=4)$ and 4 men). Subjects that reported use of antibiotics (a duration of six months) and/or 136 experienced diarrhea (a duration of one month) were excluded from the study. Average 137 characteristics of the subjects that participated in this study are shown in Table 1. Statistical 138 significance of each characteristic between groups (except gender) were assessed by One-way 139 ANOVA test, followed by a post-hoc test for unequal sample size (Tukey-kramer at a confidence 140 interval of 0.95). The Fisher's exact test was applied for a gender variable. The statistical 141 analysis was performed using an $\mathrm{R}$ software package (stat) version 3.6.1 which Benjamini142 Hochberg procedure was applied for multiple-test correction using multcomp package (version 143 1.4-10). Blood profiles, high-density lipoprotein (HDL) cholesterol and fasting glucose levels 144 were also selected for further multivariate analysis.

\section{Food frequency questionnaire}

146 Dietary intake variables were collected using food frequency questionnaire (FFQ). The 147 questionnaire contained 25 items of different food types including rice vermicelli, a traditional 148 food of northern Thailand (La-ongkham et al., 2015). Records of frequency of consumption of 
149 yogurt/ cheese/ fermented milk, and fruits were missing for one subject (lean group).

150 Frequencies were categorized into the following six levels: every day, 5-6 days a week, 3-4 days

151 a week, 1-2 days a week, less than once a week, and never. The statistical significance of

152 differences in the mean ranks among groups was determined using Kruskal-Wallis rank sum test

153 with post-hoc analysis (Dunn's test of multiple comparisons, $p$-value adjusted with the

154 Benjamini-Hochberg method (hereafter referred to as $q$-value)). The frequencies of dietary

155 consumption of each group are summarized in Table S1.

156 Fecal sample collection and DNA extraction

157 Fecal samples of all volunteers were collected in a sterilized container and immediately stored at $158-20 \cdot C$ until further use. Total genomic DNA from fecal samples was extracted using the 159 innuPREP Stool DNA Kit (Analytik Jena Biometra, Germany) following the manufacturer's 160 guidelines. Concentration and purity of DNA were evaluated on $1 \%$ agarose gels. 161 Spectrophotometry was applied to determine the DNA concentration $(\mathrm{ng} / \mu \mathrm{l})$ by the Take 3 162 Micro-Volume Plate (Biotek, USA). Total DNA per gram of fecal wet weight was calculated and 163 recorded.

\section{Amplicon generation, library preparation and sequencing}

165 The hypervariable region V3-V4 of the 16S rRNA gene was amplified using specific primers 166 (16S V3-V4: 341F: 5'-CCTAYGGGRBGCASCAG-3', 806R: 5'167 GGACTACNNGGGTATCTAAT-3') (Klindworth et al., 2013) with the barcode. All PCR 168 reactions were carried out using Phusion ${ }^{\circledR}$ High-Fidelity PCR Master Mix (New England 169 Biolabs). PCR products were run using electrophoresis on a $2 \%$ agarose gel for detection. 170 Samples that showed a band between 400-450bp were chosen for further experiments. PCR 171 products were mixed in equidensity ratios. Then, mixture PCR products were purified with 172 Qiagen Gel Extraction Kit (Qiagen, Germany). Sequencing libraries were generated using 173 NEBNext $®$ Ultra DNA Library Pre Kit for Illumina, following manufacturer 's 174 recommendations and index codes were added. Library quality was assessed using Qubit@2.0 175 Fluorometer (Thermo Scientific) and Agilent Bioanalyzer 2100 system. Libraries were 176 sequenced on the Miseq platform (Illumina, San Diego, California, United States of America) at 177 Novogene (Beijing, China) during September 2017 and 250 bp paired-end reads were generated. 
178 Further downstream steps included data analysis using Qiime (version 1.7.0), OTU clustering 179 and taxa annotation, alpha and beta diversity analysis.

\section{Data analysis}

181 Paired-end reads were assigned to samples based on their unique barcode and truncated by 182 cutting off the barcode and primer sequence. Paired-end reads were merged using FLASH 183 (V1.2.7, http://ccb.jhu.edu /software/FLASH/) (Magoč \& Salzberg, 2011). Splicing sequences 184 were called raw tags. Quality filtering on the raw tags was performed under specific filtering 185 conditions to obtain high-quality clean tags (Bokulich et al., 2013) according to the QIIME 186 (version 1.7.0, http://qiime.org/index.html) (Caporaso et al., 2012) quality-controlled process. 187 Tags were compared with the reference database (Gold database, 188 http://drive5.com/uchime/uchime_ download.html) using UCHIME algorithm (UCHIME 189 Algorithm, http:/www.drive5.com /usearch/manual/uchime_algo.html) (Edgar et al., 2011) to 190 detect chimera sequences, all of which were removed (Haas et al., 2011). The raw sequence data 191 is available at NCBI SRA with BioProject accession number PRJNA610672 (BioSample 192 accession numbers SAMN14309526 to SAMN14309555).

\section{OTU cluster and species annotation}

194 Sequence analysis was performed using Uparse software (Uparse version 1.0.1001, 195 http://drive5.com/uparse/) (Edgar, 2013). Sequences with $\geq 97 \%$ similarity were assigned to the 196 same OTU. A representative sequence for each OTU was screened for further annotation. 197 Sequences were queried against the Greengenes Database version gg.13.5 198 (http://greengenes.lbl.gov/cgi-bin/nph-index.cgi) (DeSantis et al., 2006; Wang et al., 2007) to 199 obtain taxonomic information. Newly generated OTUs were aligned using MUSCLE software 200 (Version 3.8.31, http://www. drive5.com/muscle/) (Edgar, 2004) and phylogenetic trees were 201 generated. The OTU annotation tree was visualized using a custom R package (developed by 202 Novogene Co., Ltd.). OTU abundance information was obtained by normalizing the sequence 203 number corresponding to the sample with the least sequences (OTU counts rarefied to 103744 204 reads per sample). Subsequent analysis of alpha diversity and beta diversity were all performed 205 basing on this output normalized data. The relative abundance of gut bacteria between sample 206 groups was compared by the unpaired two-samples Wilcoxon test and multiple comparisons 
207 were adjusted with Benjamini-Hochberg method $(q<0.05)$ using R software package (stats) 208 version 3.6.1.

\section{Alpha diversity}

210 Alpha diversity was applied to analyze complexity of species diversity for each sample using the 211 following indices: ACE, Chao1, observed-species, Shannon, Simpson, and Good's coverage. The 212 unpaired two-samples Wilcoxon test with Benjamini-Hochberg procedure $(q<0.05)$ was used to 213 compare alpha diversity indices between groups for statistical differences. Comparisons were 214 visualized as a box plot by ggplot2 (Wickham H, 2009) in R software (version 3.6.1).

\section{Beta diversity analysis}

216 Beta diversity analysis was used to evaluate differences of fecal samples in bacterial community 217 structure between BMI and T2DM groups. Beta diversity was calculated using both weighted 218 and unweighted unifrac. Principal Coordinate Analysis (PCoA) was performed to get principal 219 coordinates and visualize from complex, multidimensional data. PCoA analysis was displayed by 220 WGCNA package, stat package and ggplot2 package (Wickham H, 2009) in R software (version 221 2.15.3). Multi-response permutation procedure (MRPP) was used to determine dissimilarities of 222 microbial community structure between groups implemented in the $\mathrm{R}$ package vegan (version 223 2.5-6) (Mielke \& Berry, 2001). Unweighted Pair-group Method with Arithmetic Means 224 (UPGMA) Clustering was performed as a type of hierarchical clustering method to interpret the 225 distance matrix using average linkage. The relative abundance of OTUs that most likely explain 226 the differences between groups was evaluated by LEfSe (linear discriminant analysis (LDA) 227 Effect Size) analysis (Segata et al., 2011).

\section{Firmicutes/Bacteroidetes ratios}

229 The non-parametric Wilcoxon rank-sum test was performed to compare 230 Firmicutes/Bacteroidetes ratios between groups (L, OV, OB, and T2DM) $(p<0.05)$. The 231 comparisons were visualized as a boxplot by ggplot2 (Wickham H, 2009).

\section{Multivariate statistical analysis}


233 In order to gain a deeper insight into the dietary consumption profile of individuals in the 234 different groups, we used multiple factor analysis (MFA) in FactorMineR version 1.42 (R 235 software, version 3.6.1) (Lê, Josse \& Husson, 2008). MFA is beneficial for simplifying and 236 structuring variables into groups on the components (PCA-based eigenvalues). The MFA of dietary 237 consumption in different BMI and T2DM groups included 25 variables (frequency of intake) that 238 belonged to 4 variable groups (protein (8 variables), carbohydrate (6 variables), fibre (5 239 variables), and beverage (6 variables)). For evaluating the association between dietary habits, 240 blood profiles, and fecal gut bacteria in BMI and T2DM groups, 37 variables were included in 241 the MFA, which the analysis of multidimensional distance between subjects was based on 25 242 variables pattern of food consumption (frequency of intake), 2 variables described blood profiles 243 (HDL cholesterol and fasting glucose levels), and 10 variables belonged to relative abundance of 244 fecal gut microbiota at genus level. An integration of confounding factors (gender and age) with 245 other concerned variables (blood profiles, dietary habits, and fecal gut microbiota) also 246 implemented in the MFA analysis. The age variable was categorized into six groups (20-29, 30247 39, 40-49, 50-59, 60-69, and over 70) according to Png et al. (2016). Therefore, the variations 248 were revealed by the influence of each variable on the principle components. Results of 249 multivariate data analyses were extracted and visualized by Factoextra version 1.0.5. We used 250 the mixOmics R package version 6.10.2 (Rohart et al., 2017) to determine associations between 251 microbial communities, dietary consumption, and blood profiles in the different groups. We 252 applied sparse Partial Least Square (sPLS) analysis to explore relationships between these 253 variables in each study group (L, OV, OB, and T2DM). The sPLS 'canonical mode' was used to 254 specify the microbial OTU that most correlated with diets and/or blood profiles (Lê Cao et al., 255 2008, 2009). The high-dimensional data sets were visualized with clustered image maps 256 (González I et al., 2013).

\section{Results}

\section{Dietary consumption in different BMI groups and T2DM subjects}

259

260

Dietary habits of the different groups were determined to enquire whether the observed data could support the gut microbial profile. Based on the frequency of consumption records, none of the subjects in any of the groups differed in the intake of dietary protein, carbohydrate, fibre and 
262 beverage with some exceptions: significant differences were noted regarding consumption of 263 chicken (OB-T2DM comparison, $q<0.01$ ), rice vermicelli (L-T2DM comparison, $q<0.05$ ) and 264 fermented fruits or vegetables (L-OV and L-T2DM comparisons, $p<0.05$ for both).

265 The results of MFA revealed that individuals with T2DM displayed a notable variation on 266 frequency of food consumption from the rest of the groups. This was discernible on the factor 267 map indicating the first two dimensions accounting for $31.6 \%$ of variance (Fig. S1). The ellipse 268 of L, OV, and OB groups had a strong overlap compared to the ellipse representing T2DM group 269 with $95 \%$ confidence. These results indicate a lower variability of dietary consumption among 270 the different BMI groups when compared to the T2DM group (coordinate $=-1.42, p<0.001$ ).

271 The frequency of fermented fruit/vegetable consumption significantly described the first 272 dimension $(r=0.60, p<0.001)$, and that variation in food consumption among groups supported 273 the reduction of this particular type of dietary fiber intake in subjects having type 2 diabetes.

\section{Blood profiles in BMI and T2DM groups}

275 Information regarding subject status of the study is shown in Table 1. There were statistical 276 differences between the average age, BMI, weight, HDL cholesterol, and fasting glucose in four 277 study groups assessed by Tukey-kramer post-hoc test $(q<0.05)$. HDL cholesterol was 278 significantly lower in the OB groups compared to L ( $q<0.001)$, OV and T2DM groups $(q<$ $2790.05)$, and was also significantly lower in OV versus L groups $(q<0.05)$. Unsurprisingly, fasting 280 glucose level increased with increasing BMI with highest level in T2DM group $(q<0.05)$.

\section{Composition of prokaryotic fecal microbiota in BMI and T2DM groups}

282 283 284 285 286 287 288 289

A total of 3,408,383 reads were obtained from 16S rRNA amplicon sequencing with an average of 113,613 reads per sample for a total of 30 samples. Using $97 \%$ identity criterion for determining OTUs, we obtained $504.33 \pm 33.15$ OTUs per sample (range 454-579 OTUs). Gut microbiota of all samples was classified into 995 OTUs, 145 genera, 82 families, 53 orders, 31 classes and 18 phyla. Shared and unique OTUs among different groups are shown in Venn diagram (Fig. 1). The total number of OTUs presented in the L, OV, OB, and T2DM groups were $832,811,753,852$, respectively. The number of shared OTUs in all groups was $588 ; 729$ OTUs (22.44\%) were shared between L and OV groups, 752 OTUs (23.15\%) between L and 
290 T2DM groups, 671 (20.65\%) between L and OB groups, 730 (22.48\%) between OV and T2DM 291 groups, 657 (20.22\%) between OV and OB groups, and 629 (19.37\%) between T2DM and OB 292 groups (Fig. 1A). Regarding the number of non-shared OTUs, non-diabetic subjects (merging 293 OTUs of L, OV, and OB groups) had four times more than diabetic subjects (T2DM). 294 Specifically, 139 non-shared OTUs (17\%) were associated with the non-diabetic group, whereas 29533 OTUs (4\%) were uniquely present in T2DM subjects (Fig. 1B). The rarefaction curves of 296 microbial diversity estimators for thirty samples reached plateau phase, indicating that most 297 microbial species had been detected in all samples (Figs. S2A-2C).

298 Fecal microbiome community diversity (richness and evenness) in the four groups was 299 characterized using ACE, Chao1, observe-species, Shannon, Simpson, and Good's coverage. 300 Sequencing data and alpha diversity indices in each sample are presented in Table S2 and S3. 301 Significant differences of overall bacterial community structure across the four groups were 302 found in the ACE, Chao1, and observe-species indices (Fig. 2). Specifically, microbial 303 communities of L and T2DM groups had significantly greater species richness as compared to 304 those in OB. No significant differences in the diversity of communities (species richness and 305 evenness) were found across the four groups by Shannon and Simpson indices, suggesting a 306 similar pattern of the community composition in all groups. Nevertheless, microbial 307 communities of all four groups had high species-level diversity as indicated by Simpson index, 308 the value of which approached 1. This implies that as species richness and evenness increased, 309 diversity also increased.

310 The top ten phyla of microbial communities across the four groups were Bacteroidetes, 311 Firmicutes, Proteobacteria, Fusobacteria, Actinobacteria, Verrucomicrobia, Cyanobacteria, 312 Tenericutes, Elusimicrobia, and TM7. No significant differences were detected among groups ( $p$ $313<0.05)$ (Figs. S3A, 3B). Top ten of bacterial genera with high relative abundance were used to 314 construct phylogenetic relationships (Fig. S3C). Based on the similarity threshold, some bacterial 315 species related to Prevotella genus were clustered in [Prevotella] as their discrete lineages 316 distinct from other known species within this genus. The representative OTUs assembled in 317 [Prevotella] consist of Prevotella tannerae (1 OTU), Uncultured bacterium (7 OTUs) and 318 Prevotellamassilia timonensis (2 OTUs). The latter is a newly identified bacterial species in the 319 human gut (Ndongo et al., 2016) 
320

321

322

323

324

325

326

327

328

329

330

331

332

333

334

335

336

337

338

339

340

341

342

343

344

345

346

347

348

349

We further compared the median differences of the Firmicutes:Bacteroidetes ratios between groups with 95\% confidence interval at phylum level (Fig. S3D). No statistically significant difference was noted among any of the groups. Among the top ten dominant genera, Prevotella and Bacteroides accounted for the largest proportion in all sample groups (Figs. 3A, 3B). Several significant differences among the dominant taxa were also found without the BenjaminiHochberg method. Faecalibacterium showed significant differences in OV-OB $(p=0.044)$ and OB-T2DM ( $p=0.011)$ comparisons (Fig. 3C), while [Prevotella] differed in L and OV comparison ( $p=0.034$ ) (Fig. 3D). Gut microbial alterations at species levels in four groups of samples (Fig. S4A, 4B) present significant differences of butyrate-producing bacteria (Faecalibacterium prausnitzii) in OV-OB $(p=0.044)$ and OB-T2DM $(p=0.011)$ comparisons (Fig. S4C), whereas there was a statistically significant difference between OV and T2DM group $(p=0.026)$ with respect to the relative abundance of Prevotella copri (Fig. S4D). Bacteroides coprophilus was also significantly different in OV-OB $(p=0.026)$ and OV-T2DM comparisons $(p=0.015)$. Analysis of statistical differences of microbial species abundance among groups by LEfSe showed marked differences between subject groups (Fig. 4). In the histogram, the colors represent taxa that were found to be more abundant in OB group compared to the other groups (both for the positive (green/blue) and the negative score (red)). In this regard, there were six taxa (Veillonellaceae, Prevotella, Dialister, Megamonas, Faecalibacterium, and Faecalibacterium prausnitzii), two genera (Clostridium and Prevotella) and one species (Bacteroides coprophilus) enriched in OB, T2DM and OV groups, respectively, while no enrichment of species was noted in the L group.

\section{Beta diversity analysis of fecal microbiota in BMI and T2DM groups}

Qualitative (unweighted UniFrac) and quantitative beta (quantitative measure) diversity measures yielded substantially different perspectives on the factors (BMI groups and/or the disease) that may be involved in structuring bacterial diversity. Unweighted UniFrac showed less distance of samples than Weighted UniFrac (Fig. S5B). PCoA based on Unweighted UniFrac revealed clearer patterns of microbial variation (Fig. 5B). Gut microbial communities in OB group were significantly different from those of the T2DM group $(p<0.05)$, whereas no dissimilarity was observed in comparison with other groups. Furthermore, more similar community composition was observed in OB and OV groups with some overlaps also identified 
350 by UPGMA (Fig. S5B). Clustering analysis suggested association of BMI and/or a disease with

351 the variations in bacterial community compositions among subjects. Conversely, PCoA and 352 weighted UniFrac did not clearly discriminate microbial communities among groups implying 353 that there was no strong association with BMI and/or T2DM in this population (Fig. 5A). When 354 taking the relative abundance of each type of OTUs into account, the results displayed 355 similarities in bacterial composition, suggesting that indistinguishable communities may result 356 from the number of organisms collected in the dominant phylum (Firmicutes, Bacteroidetes and 357 Proteobacteria) (Fig. S5A).

358

359

360

361

362

363

364

365

366

367

368

369

370

371

372

373

374

375

376

377

378

379

\section{Associations between dietary habits, blood profiles, and fecal gut microbiota in BMI and T2DM groups}

MFA revealed the variables that mostly contributed in explaining the variations regarding dietary habits, blood profiles, and the relative abundance of gut microbiota of subjects in different BMI groups as well as the T2DM group. The factor map of the MFA generated by data integration of all variables showed the significance of Dim 1 and 2 that explained $14.3 \%$ and 12.8 of observed variability, respectively (Fig. 6). The distinct or similar profile of individuals, indicated by the ellipses on both axes of the MFA, mainly resulted from the variation in the blood profiles: HDL cholesterol levels were lower in the $\mathrm{OB}$ group than those observed in the other groups (coordinate $=-1.20, p<0.05)$ and higher fasting glucose levels were firmly correlated with T2DM (coordinate $=-1.54, p<0.001$ ) in comparison with the BMI groups. In addition to the blood profiles, the genera of bacteria that associated with Dim 1 included Fusobacterium $(r=$ 0.55, $p<0.01)$, Bacteroides $(r=0.52, p<0.01)$, Prevotella $(r=-0.54, p<0.01)$, and Faecalibacterium $(r=-0.47, p<0.01)$. Fusobacterium was associated with $\operatorname{Dim} 2(r=0.47, p<$ 0.01). For dietary consumption, dairy products and mixed rice variables were negatively correlated with $\operatorname{Dim} 1(r=-0.63, p<0.001)$ and $\operatorname{Dim} 2(r=-0.64, p<0.001)$, respectively. The second dimension was described by a beef variable with a correlation coefficient of 0.53 ( $p<$ 0.01). The relationships of the relative abundance of gut bacteria and the frequency of food intake were nevertheless interpreted as moderate correlation to both dimensions (moderate variance). Concerning the contribution of all variables to describe the differences between individuals, the current analysis suggested that blood profiles seemed to have most influence on the variability of 30 subjects with different BMIs or with T2DM. Furthermore, the association 
380 between dietary intake, blood profiles, and microbial OTUs at the genus level from sPLS 381 analysis are additionally summarized in Table 2.

382 Gender and age highly contributed to the variations of subjects in different BMI groups and 383 T2DM group (Fig. S6). Integration of five variables (gender, age, blood profiles, dietary

384 385 386 387 388 389 390 391 392 393 394 395 396 397 398 399 400

401

402 403 404 405 406 407 408 409 410 consumption, and the relative abundance of gut microbiota) by the MFA revealed that gender and age were the top two variables that highly explained individual variation in terms of blood profiles, dietary consumption, and the relative abundance of gut microbiota. The opposed pattern of T2DM females (coordinate $=-3.12, p<0.001)$ at age levels of four (50-59) and five (60-69) to Dim 1 was explained by the consumption of fish $(r=-0.82, p<0.001)$, whereas the consumption of fermented fruits or vegetables $(r=0.52, p<0.01)$ and dairy products $(r=0.51, p$ $<0.01)$ as well as the abundance of Faecalibacterium $(r=0.49, p<0.01)$ tended to be prevalent in OB females (coordinate $=1.92, p<0.05$ ). HDL cholesterol levels were negatively correlated to Dim $2(-0.78)$, particularly among $\mathrm{L}$ females (coordinate $=-3.0, p<0.001$ ) at the age level of three $(40-49)$ (coordinate $=-2.58, p<0.001)$ that displayed higher HDL profile than OB and T2DM. In Dim 3, Escherichia was moderately correlated to the dimension $(r=0.51, p<0.01)$ and was predominant in $\mathrm{OB}$ male at the age of 71 (coordinate $=3.25, p<0.01$ ). The distinct pattern of T2DM females marked in Dim 4 (coordinate $=1.52, p<0.05$ ) resulted from high fasting glucose levels with the correlation dimension of $(r=0.51, p<0.01)$.

When all blood tests were taken into account, several important variables were maintained (Fig. S7), however, their variations were described by different dimensions as compared to the MFA in Fig S6. Different profiles between OB females and T2DM females were illustrated in $\operatorname{Dim} 1$, where the consumption of chicken $(r=0.70, p<0.001)$, dairy products $(r=0.59, p<$ 0.001 ), and the abundance of Faecalibacterium $(r=0.53, p<0.01)$ were less prevalent among T2DM females (coordinate $=-2.99, p<0.001)$ in comparison with OB females (coordinate $=$ 2.21, $p<0.01$ ). A distinct cluster of $\mathrm{L}$ females observed in Dim 2 (coordinate $=-2.65, p<$ $0.001)$ was mostly described by HDL cholesterol levels $(r=-0.72, p<0.001)$ as being analogous to Dim 2 of Fig. S6. A moderate correlation of Escherichia dimension $(r=0.42, p<$ 0.05 ) also displayed in Dim 2 in parallel with OB male at the age of 71 (coordinate $=3.22, p<$ $0.01)$. Faecalibacterium $(r=0.44, p<0.05)$ and FBS $(r=0.37, p<0.05)$, however consistently presented in Dim 3, was predominant in OB females (coordinate $=1.90, p<0.05$ ). Interestingly, most OV individuals were negatively correlated with Dim 2 as resulted from LDL cholesterol 
411 levels $(r=-0.45, p<0.05)$ that tended to be higher in both OV male (coordinate $=-2.92, p<$ 4120.05 ) and females (coordinate $=-1.51, p<0.001$ ), especially at the age level of two (30-39) 413 (coordinate $=-2.10, p<0.001$ ).

414 Exclusion of gender and age variables showed a strong overlap of non-diabetic (BMIs) and 415 diabetic (T2DM) subjects, though no specific group was defined in relation to the variations of 416 blood profiles and gut microbiota, indicating dispersal of variables across BMI and T2DM 417 groups (Fig. S8). In Dim 1, the distribution of subjects on the MFA map was mainly influenced 418 by the abundance of three major genera including Bacteroides $(r=0.68, p<0.001)$, Prevotella $(r$ $419=-0.65, p<0.001)$, and Faecalibacterium $(r=-0.65, p<0.001)$. Cholesterol $(r=0.49, p<$ $4200.01)$, triglyceride $(r=0.43, p<0.05)$, and diastolic blood pressure $(r=0.43, p<0.05)$ levels 421 moderately correlated with the dimension. Furthermore, systolic blood pressure $(r=0.68, p<$ $4220.001)$ and HDL cholesterol $(r=-0.54, p<0.01)$ levels mainly described the individual variance 423 in the second dimension.

\section{Discussion}

425 Our study provides the first evaluation of bacterial gut microbiota composition in adult Thai 426 subjects of various BMI and T2DM. Microbial diversity across four groups was examined using 427 six indices based on richness and evenness. The BMI between OB-L and OB-T2DM, OB group 428 was associated with a significant decrease in bacterial diversity across three indices (ACE, 429 Chao1, and observed species), whereas a change of diversity was maintained in L and T2DM 430 groups. This is in agreement with the previous study of Chinese subjects with different glucose 431 intolerance statuses (normal glucose tolerance, prediabetes, T2DM) (Zhang et al., 2013). The

432 observed reduced-bacterial diversity in OB groups is consistent with previous findings, in that 433 obese subjects exhibited lower alpha diversity, when compared with non-obese subjects 434 (Turnbaugh et al., 2009; Le Chatelier et al., 2013). Accordingly, obese individuals in a Korean 435 population displayed lower gut bacterial diversity (phylogenetic diversity index) than normal 436 weight and overweight individuals (Yun et al., 2017). Yet this was not consistently the case in 437 terms of BMI categories. An investigation of fecal microbiome in a large Chinese cohort 438 displayed no dissimilarity of alpha diversity among BMI groups (Gao et al., 2018). Similar 439 results were also obtained in two studies that assessed the upper digestive tract microbiome (Lin 
440 et al., 2015; Angelakis et al., 2015). Neither of these studies revealed an association between 441 microbial diversity and BMI. These inconsistent findings with respect to bacterial diversity and 442 its association with BMI, might not only be due to the small sample size used in our study, but 443 also other parameters such as age, gender, and dietary consumption. Despite the above444 mentioned bacterial richness estimators, OTU-level alpha diversity calculations by Shannon and 445 Simpson indices yielded no significant difference in gut microbe diversity and richness, 446 indicating low among-group (BMIs and T2DM) dissimilarities, which may suggest that a change 447 of gut microbial composition might be affected by BMI or T2DM at the low taxonomic level.

448 Similar to previous studies (Duncan et al., 2008; Yun et al., 2017; Peters et al., 2018), there 449 was no significant difference of the Firmicutes:Bacteroidetes ratio between BMI groups.

450 Previous studies have yielded contradictory results with regard to a link between the ratio of 451 Firmicutes:Bacteroidetes and obesity (Gomes, Hoffmann \& Mota, 2018; Tseng CH\& Wu CY, 452 2019). For example, higher Firmicutes:Bacteroidetes ratios were found in obese compared with 453 non-obese Japanese subjects, and both in overweight and obese Ukrainians, respectively (Kasai 454 et al., 2015; Koliada et al., 2017). In contrast, Schwiertz et al. (2010) found a lower proportion 455 of Firmicutes compared to Bacteroidetes in overweight and obese volunteers. Besides these two 456 predominant phyla, Prevotella and Bacteroides, were enriched in OB and T2DM, and in OV, 457 respectively Enrichment of these taxa indicates enterotypes and these are likely the result of 458 individual dietary characteristics. The presence of enterotypes in Thais has been previously 459 shown and attributed to different diet types like vegetarians and non-vegetarians 460 (Ruengsomwong et al., 2016). With regard to dominant gut microbiota variations, such as 461 Firmicutes (high-fiber and carbohydrate foods) and Bacteroidetes (high-calorie foods, such as 462 animal proteins and foods rich in fats), inconsistent results across studies could be explained by a 463 variety of dietary components (Western or Asian diet) that may influence dynamics of gut 464 microbiome. Therefore, detailed dietary data should be included in future research for a more 465 comprehensive understanding of the links between dietary patterns and gut microbiota profiles.

Although we found similar profiles of the major gut bacterial phyla across the four groups, 467 this was not the case in all taxonomic ranks. For example, F. prausnitzii, butyrate-producing 468 bacteria, was more abundant in the OB subjects as compared to T2DM. Alteration of the gut 469 microbiome marked by an increase of $F$. prausnitzii in obese or a decrease of this bacterial 470 species in T2DM subjects has been demonstrated in several studies. Our finding is in parallel to 
471 an increase of $F$. prausnitzii in obese Indian and Mexican children (Balamurugan et al., 2010;

472 Murugesan et al., 2015). A lower prevalence of this bacterium was also observed in T2DM

473 Chinese patients in comparison with that of non-diabetic subjects (Qin et al., 2012). High

474 accumulation of this butyrate producer in OB group may reflect the energy expenditure of the

475 host with regard to the mechanism of its major metabolite (butyrate) in engaging host

476 metabolism. The proof of concept for such interaction has been immensely demonstrated in an

477 animal model (De Vadder et al., 2014; Den Besten et al., 2015) as well as in humans (Turnbaugh

478 et al., 2006; den Besten et al., 2013). Although the pros and cons of butyrate towards obesity has

479 been reviewed, the capability of butyrate in influencing lipid biosynthesis could contribute to

480 obesity (Liu et al., 2018). Collectively, these evidence highlight that the butyrate-producing

481 species might be an indicator of host physiology.

482 Trends in associations between gut microbiota with some food groups and blood parameters

483 were observed in the dominant taxa, particularly with members of Firmicutes and Bacteroidetes

484 phyla. Prevotella and [Prevotella] were correlated with carbohydrate-rich and fibre-rich diets in

485 OB and T2DM subjects, while their links with plant-based foods have been previously described

486 (Kovatcheva-Datchary P et al., 2015; Ruengsomwong et al., 2016; Kisuse et al., 2018a).

487 Moreover, Prevotella enterotype is generally dominant in Asian countries, where traditional high

488 fibre diets are preferable, in contrast to Western countries, where food consumption is more

489 homogenous (except Mediterranean diet) and mainly relies on high fat and protein content

490 (Senghor et al., 2018). The differences in gut microbiota have been previously reported in

491 representative Indian and Chinese subjects, as well as, Japanese populations. Variability in diets

492 across Asia along with its geographically unique pattern contributes substantially to differences

493 in the composition of gut bacteria communities observed in diverse Asian populations and/or

494 ethnicities (Senghor et al., 2018; Jain, Li \& Chen, 2018; Pareek et al., 2019). Notably,

495 consumption of some types of foods (chicken, rice vermicelli, and fermented fruits or

496 vegetables) was considerably lower in T2DM subjects than in any of the BMI groups. This is

497 consistent with diabetic subjects being more concerned about food consumption (high

498 cholesterol, carbohydrate, and sodium) and increased risk of complications of diabetes

499 (Yannakoulia, 2006; Valensi \& Picard, 2011; Provenzano et al., 2014; Sami et al., 2017).

500 Although Bacteroidetes is well known to be associated with protein/fat diets ( Wu et al., 2011), a

501 positive correlation with brown rice was found in OB subjects. Whilst we did not specifically

Peer] reviewing PDF | (2020:03:46544:1:0:NEW 7 Jun 2020) 
502 identify the species, there is evidence suggesting that an increase in abundance of some

503 Bacteroides strains results from competition with other members for fibre-derived nutrients

504 (Hindson, 2019). With respect to small numbers of subjects used in our study, the positive

505 relationship of abundances of butyrate-producing bacteria (Roseburia and Faecalibacterium)

506 with fasting glucose levels of different groups (L, OV, and T2DM) may not sufficiently explain

507 the association between these bacteria and the presence of glucose. The low abundance of these

508 genera in T2DM patients has been previously reported (Qin et al., 2012; Karlsson et al., 2013).

509 Recent studies based on sequencing technology have examined the impact of gender and

510 BMI on the status of gut microbiota (Dominianni et al., 2015; Haro et al., 2016; Borgo et al.,

511 2018) including an aging-related decrease in gut bacteria (Shen et al., 2018; Takagi et al., 2019;

$512 X u, Z h u \& Q i u, 2019)$. However, our study is limited by gender-disproportionate recruitment, the

513 age range of subjects, the variations of BMI in T2DM groups as well as, the sample size. Thus,

514 the observed variations among different BMI groups and T2DM subjects were apparently

515 influenced by several variables associated with female subjects. According to the MFA factor

516 map for individuals, inclusion of confounding variables (gender, age, and diets) together with

517 blood profiles and the relative abundance of gut microbiota showed a contrary pattern between

$518 \mathrm{OB}$ and T2DM. The consumption of fermented fruits or vegetables, chicken, dairy products

519 along with the relative abundance of Faecalibacterium prevailed among OB females (made up of

520 three women with the average age of 34), whereas a diminishing trend was displayed in older

521 T2DM females (made up of six women with the average age of 60) with a high fasting glucose

522 level. The worldwide trend in diabetes prevalence, including Thailand, has increased in adults

523 over the age of 50 (Wild et al., 2004; Aekplakorn et al., 2018). Based on the average age of these

524 two groups, OB and T2DM females seemed to differ considerably in terms of age-related

525 changes in hormone levels. Some evidence has shown that the alteration of gut microbiota

526 composition may be driven by the postmenopausal loss of estrogen (Vieira et al., 2017). In this

527 study, all T2DM female subjects are postmenopausal, which the condition naturally relies on

528 age(Agostini et al., 2018), our study suggests that a menstrual condition according to the age of

529 the subjects should be further considered when investigating the gut microbiota profiles. In

530 addition to other concerned factors including blood profiles, diets, BMI levels, and T2DM, the

531 study itself may not support such a clear conclusion on the difference in the relative abundance

532 of Faecalibacterium derived from the age differences in subjects. A possible aspect that could be 
533 drawn from such differences marked in OB and T2DM may be the specificity of metabolic

534 diseases in gut bacteria associations (Festi et al., 2014; Gurung et al., 2020). Considering all

535 blood profiles in association with fecal gut microbiota (irrespective of gender and age), neither

536 the blood profiles nor the gut microbiome influenced on a specific group of subjects. Besides, the

537 individual differences shown on the MFA were resulted from some bacterial genera

538 (Bacteroides, Prevotella, and Faecalibacterium) and blood profiles (total cholesterol,

539 triglyceride, and diastolic blood pressure, systolic blood pressure, and HDL cholesterol) that only

540 contributed to the variation of subjects. Evidence for the involvement of gut microbiome in

541 metabolic disorders that posed either a detriment (Dabke, Hendrick \& Devkota, 2019; Gildner,

542 2020) or a benefit to host health (He \& Shi, 2017) encourage further study to increase the sample

543 size as our conclusion might not be applicable for the study with a large population. Therefore,

544 this adjustment may help to facilitate explaining the explanation of associations between blood

545 profiles and the gut bacteria.

546

547 Conclusions

548 Our study has provided a preliminary overview of prokaryotic communities in the gut of adult

549 Thais, regardless of the small sample size. Associations between dietary intake, blood profiles, 550 and fecal gut microbiome in different BMI and T2DM subjects were also examined. A range of 551 multivariate data analysis (MFA and sPLS) enabled us to capture the profiles of individuals in 552 each study group. Subjects with obesity and/or diabetes might be associated with different 553 bacterial populations when linking with dietary consumption and blood profiles. However, a 554 larger sample size is mandatory to advance an understanding of the interplay of BMI or T2DM to 555 changes of microbiota composition, together with metabolomics data. Validation of abundance 556 of considered taxa related to BMIs by qPCR should be additionally included in future research.

557

558 Acknowledgements

559 The authors would like to thank all volunteers for providing dietary consumption data, blood and 560 fecal samples. We would like to thank Mr. Tawatchai Chumponsuk for technical assistance. We 561 would like to thank Associate Professor Jiro Nakayama for useful comments. We thank Dr. Eleni 562 Gentekaki for useful discussions and editing of this manuscript. 


\section{References}

565 Aekplakorn W, Chariyalertsak S, Kessomboon P, Assanangkornchai S, Taneepanichskul S,

566 Putwatana P. 2018. Prevalence of diabetes and relationship with socioeconomic status in the

567

568 Thai population: National health examination survey, 2004?2014. Journal of Diabetes

569 Research 2018:1654530. DOI: 10.1155/2018/1654530.

Agostini D, Zeppa SD, Lucertini F, Annibalini G, Gervasi M, Marini CF, Piccoli G, Stocchi V,

570 Barbieri E, Sestili P. 2018. Muscle and bone health in postmenopausal women: Role of

571 protein and vitamin d supplementation combined with exercise training. Nutrients 10 . DOI:

572 10.3390/nu10081103.

573

Ahmad A, Yang W, Chen G, Shafiq M, Javed S, Zaidi SSA, Shahid R, Liu C, Bokhari H. 2019.

574

575

576

Al-Goblan AS, Al-Alfi MA, Khan MZ. 2014. Mechanism linking diabetes mellitus and obesity.

577

578

579

580

581

582

583

584 Analysis of gut microbiota of obese individuals with type 2 diabetes and healthy individuals. PLoS ONE 14:e0226372-. DOI: 10.1371/journal.pone.0226372. Diabetes, metabolic syndrome and obesity : targets and therapy 7:587-591. DOI:

10.2147/DMSO.S67400.

Angelakis E, Armougom F, Carrière F, Bachar D, Laugier R, Lagier J-C, Robert C, Michelle C, Henrissat B, Raoult D. 2015. A Metagenomic Investigation of the Duodenal Microbiota Reveals Links with Obesity. PLOS ONE 10:e0137784-.

Bäckhed F, Ley RE, Sonnenburg JL, Peterson DA, Gordon JI. 2005. Host-bacterial mutualism in the human intestine. Science (New York, N.Y.) 307:1915-1920. DOI:

585

586

Balamurugan R, George G, Kabeerdoss J, Hepsiba J, Chandragunasekaran AMS, Ramakrishna

587 BS. 2010. Quantitative differences in intestinal Faecalibacterium prausnitzii in obese Indian

587

588

589

590

591 children. British Journal of Nutrition 103:335-338. DOI: 10.1017/S0007114509992182.

Bays HE, Chapman RH, Grandy S. 2007. The relationship of body mass index to diabetes mellitus, hypertension and dyslipidaemia: Comparison of data from two national surveys. International Journal of Clinical Practice 61:737-747. DOI: 10.1111/j.1742-

592 1241.2007.01336.x.

593

Belizário JE, Faintuch J. 2018. Microbiome and Gut Dysbiosis. Experientia supplementum (2012) 109:459-476. DOI: 10.1007/978-3-319-74932-7_13.

Den Besten G, Bleeker A, Gerding A, Van Eunen K, Havinga R, Van Dijk TH, Oosterveer MH, 
595

596

597

598

599

600

601

602

603

604

605

606

607

608

609

610

611

612

613

614

615

616

617

618

619

620

621

622

623

624

625

Jonker JW, Groen AK, Reijngoud DJ, Bakker BM. 2015. Short-chain fatty acids protect against high-fat diet-induced obesity via a pparg-dependent switch from lipogenesis to fat oxidation. Diabetes 64:2398-2408. DOI: 10.2337/db14-1213.

den Besten G, Lange K, Havinga R, van Dijk TH, Gerding A, van Eunen K, Müller M, Groen AK, Hooiveld GJ, Bakker BM, Reijngoud DJ. 2013. Gut-derived short-chain fatty acids are vividly assimilated into host carbohydrates and lipids. American Journal of Physiology Gastrointestinal and Liver Physiology 305:G900-G910. DOI: 10.1152/ajpgi.00265.2013.

Bokulich NA, Subramanian S, Faith JJ, Gevers D, Gordon JI, Knight R, Mills DA, Caporaso JG. 2013. Quality-filtering vastly improves diversity estimates from Illumina amplicon sequencing. Nature Methods 10:57-59. DOI: 10.1038/nmeth.2276.

Borgo F, Garbossa S, Riva A, Severgnini M, Luigiano C, Benetti A, Pontiroli AE, Morace G, Borghi E. 2018. Body mass index and sex affect diverse microbial niches within the gut. Frontiers in Microbiology 9:213. DOI: 10.3389/fmicb.2018.00213.

Bubnov R V, Babenko LP, Lazarenko LM, Mokrozub V V, Demchenko OA, Nechypurenko O V, Spivak MY. 2017. Comparative study of probiotic effects of Lactobacillus and Bifidobacteria strains on cholesterol levels, liver morphology and the gut microbiota in obese mice. EPMA Journal 8:357-376. DOI: 10.1007/s13167-017-0117-3.

Bull MJ, Plummer NT. 2014. Part 1: The Human Gut Microbiome in Health and Disease. Integrative medicine (Encinitas, Calif.) 13:17-22.

Caballero B. 2007. The global epidemic of obesity: An overview. Epidemiologic Reviews 29:15. DOI: $10.1093 / \mathrm{epirev} / \mathrm{mxm} 012$.

Caporaso JG, Lauber CL, Walters WA, Berg-Lyons D, Huntley J, Fierer N, Owens SM, Betley J, Fraser L, Bauer M, Gormley N, Gilbert JA, Smith G, Knight R. 2012. Ultra-highthroughput microbial community analysis on the Illumina HiSeq and MiSeq platforms. The ISME journal 6:1621-1624. DOI: 10.1038/ismej.2012.8.

Carding S, Verbeke K, Vipond DT, Corfe BM, Owen LJ. 2015. Dysbiosis of the gut microbiota in disease. Microbial Ecology in Health \& Disease 26:26191. DOI:

10.3402/mehd.v26.26191.

Le Chatelier E, Nielsen T, Qin J, Prifti E, Hildebrand F, Falony G, Almeida M, Arumugam M, Batto J-M, Kennedy S, Leonard P, Li J, Burgdorf K, Grarup N, Jørgensen T, Brandslund I, Nielsen HB, Juncker AS, Bertalan M, Levenez F, Pons N, Rasmussen S, Sunagawa S, Tap 
626

627

628

629

630

631

632

633

634

635

636

637

638

639

640

641

642

643

644

645

646

647

648

649

650

651

652

653

654

655

656

J, Tims S, Zoetendal EG, Brunak S, Clément K, Doré J, Kleerebezem M, Kristiansen K, Renault P, Sicheritz-Ponten T, de Vos WM, Zucker J-D, Raes J, Hansen T, consortium M, Bork P, Wang J, Ehrlich SD, Pedersen O. 2013. Richness of human gut microbiome correlates with metabolic markers. Nature 500:541-546. DOI: 10.1038/nature12506.

Clemente JC, Ursell LK, Parfrey LW, Knight R. 2012. The impact of the gut microbiota on human health: An integrative view. Cell 148:1258-1270. DOI: 10.1016/j.cell.2012.01.035.

Dabke K, Hendrick G, Devkota S. 2019. The gut microbiome and metabolic syndrome. Journal of Clinical Investigation 129:4050-4057. DOI: 10.1172/JCI129194.

David LA, Maurice CF, Carmody RN, Gootenberg DB, Button JE, Wolfe BE, Ling A V, Devlin AS, Varma Y, Fischbach MA, Biddinger SB, Dutton RJ, Turnbaugh PJ. 2014. Diet rapidly and reproducibly alters the human gut microbiome. Nature 505:559-563. DOI: 10.1038 /nature 12820 .

DeSantis TZ, Hugenholtz P, Larsen N, Rojas M, Brodie EL, Keller K, Huber T, Dalevi D, Hu P, Andersen GL. 2006. Greengenes, a chimera-checked 16S rRNA gene database and workbench compatible with ARB. Applied and environmental microbiology 72:5069-5072. DOI: 10.1128/AEM.03006-05.

Dominianni C, Sinha R, Goedert JJ, Pei Z, Yang L, Hayes RB, Ahn J. 2015. Sex, body mass index, and dietary fiber intake influence the human gut microbiome. PLoS ONE 10:e0124599-e0124599. DOI: 10.1371/journal.pone.0124599.

Drewnowski A. 2009. Obesity, diets, and social inequalities. In: Nutrition Reviews. John Wiley \& Sons, Ltd, S36-S39. DOI: 10.1111/j.1753-4887.2009.00157.x.

Duncan SH, Lobley GE, Holtrop G, Ince J, Johnstone AM, Louis P, Flint HJ. 2008. Human colonic microbiota associated with diet, obesity and weight loss. International journal of obesity (2005) 32:1720-1724. DOI: 10.1038/ijo.2008.155.

Edgar RC. 2004. MUSCLE: multiple sequence alignment with high accuracy and high throughput. Nucleic acids research 32:1792-1797. DOI: 10.1093/nar/gkh340.

Edgar RC. 2013. UPARSE: highly accurate OTU sequences from microbial amplicon reads. Nature methods 10:996-998. DOI: 10.1038/nmeth.2604.

Edgar RC, Haas BJ, Clemente JC, Quince C, Knight R. 2011. UCHIME improves sensitivity and speed of chimera detection. Bioinformatics (Oxford, England) 27:2194-2200. DOI: 10.1093/bioinformatics/btr381. 
657 Everard A, Belzer C, Geurts L, Ouwerkerk JP, Druart C, Bindels LB, Guiot Y, Derrien M, 658 Muccioli GG, Delzenne NM, De Vos WM, Cani PD. 2013. Cross-talk between

659

660

661

662

663

664

665

666

667

668

669

670

671

672

673

674

675

676

677

678

679

680

681

682

683

684

685

686

687

Akkermansia muciniphila and intestinal epithelium controls diet-induced obesity. Proceedings of the National Academy of Sciences of the United States of America 110:9066-9071. DOI: 10.1073/pnas.1219451110.

Festi D, Schiumerini R, Eusebi LH, Marasco G, Taddia M, Colecchia A. 2014. Gut microbiota and metabolic syndrome. World Journal of Gastroenterology 20:16079-16094. DOI: 10.3748/wjg.v20.i43.16079.

Flint HJ, Scott KP, Louis P, Duncan SH. 2012. The role of the gut microbiota in nutrition and health. Nature reviews. Gastroenterology \& hepatology 9:577-589. DOI: 10.1038/nrgastro.2012.156.

Ganz ML, Wintfeld N, Li Q, Alas V, Langer J, Hammer M. 2014. The association of body mass index with the risk of type 2 diabetes: a case-control study nested in an electronic health records system in the United States. Diabetology \& metabolic syndrome 6:50. DOI: 10.1186/1758-5996-6-50.

Gao X, Zhang M, Xue J, Huang J, Zhuang R, Zhou X, Zhang H, Fu Q, Hao Y. 2018. Body Mass Index Differences in the Gut Microbiota Are Gender Specific. Frontiers in microbiology 9:1250. DOI: 10.3389/fmicb.2018.01250.

Gauffin Cano P, Santacruz A, Moya Á, Sanz Y. 2012. Bacteroides uniformis CECT 7771 ameliorates metabolic and immunological dysfunction in mice with high-fat-diet induced obesity. PLOS ONE 7:e41079-e41079. DOI: 10.1371/journal.pone.0041079.

Gildner TE. 2020. Links between metabolic syndrome and the microbiome. Evolution, Medicine, and Public Health 2020:45-46. DOI: 10.1093/emph/eoaa007.

Gomes AC, Hoffmann C, Mota JF. 2018. The human gut microbiota: Metabolism and perspective in obesity. Gut Microbes 9:308-325. DOI: 10.1080/19490976.2018.1465157.

González I, Lê Cao KA, Davis MD, Déjean S. 2013. Insightful graphical outputs to explore relationships between two 'omics' data sets. BioData Mining 5:19.

Gray N, Picone G, Sloan F, Yashkin A. 2015. Relation between BMI and diabetes mellitus and its complications among US older adults. Southern medical journal 108:29-36. DOI: 10.14423/SMJ.0000000000000214.

Gurung M, Li Z, You H, Rodrigues R, Jump DB, Morgun A, Shulzhenko N. 2020. Role of gut 
688

689

690

691

692

693

694

695

696

697

698

699

700

701

702

703

704

705

706

707

708

709

710

711

712

713

714

715

716

717

718

microbiota in type 2 diabetes pathophysiology. EBioMedicine 51. DOI:

10.1016/j.ebiom.2019.11.051.

Haas BJ, Gevers D, Earl AM, Feldgarden M, Ward D V, Giannoukos G, Ciulla D, Tabbaa D, Highlander SK, Sodergren E, Methé B, DeSantis TZ, Consortium HM, Petrosino JF, Knight R, Birren BW. 2011. Chimeric 16S rRNA sequence formation and detection in Sanger and 454-pyrosequenced PCR amplicons. Genome research 21:494-504. DOI: $10.1101 /$ gr. 112730.110 .

Han SJ, Boyko EJ. 2018. The Evidence for an Obesity Paradox in Type 2 Diabetes Mellitus. Diabetes \& metabolism journal 42:179-187. DOI: 10.4093/dmj.2018.0055.

Haro C, Rangel-Zúñiga OA, Alcalá-Díaz JF, Gómez-Delgado F, Pérez-Martínez P, DelgadoLista J, Quintana-Navarro GM, Landa BB, Navas-Cortés JA, Tena-Sempere M, Clemente JC, López-Miranda J, Pérez-Jiménez F, Camargo A. 2016. Intestinal microbiota is influenced by gender and body mass index. PLoS ONE 11:e0154090-e0154090. DOI: 10.1371/journal.pone.0154090.

Harrison CA, Taren D. 2018. How poverty affects diet to shape the microbiota and chronic disease. Nature Reviews Immunology 18:279-287. DOI: 10.1038/nri.2017.121.

He M, Shi B. 2017. Gut microbiota as a potential target of metabolic syndrome: The role of probiotics and prebiotics. Cell and Bioscience 7:54. DOI: 10.1186/s13578-017-0183-1.

Hindson J. 2019. Bacteroides compete for fibre-derived glycans. Nature Reviews Gastroenterology \& Hepatology 16:706-707. DOI: 10.1038/s41575-019-0223-X.

Hughes RL, Marco ML, Hughes JP, Keim NL, Kable ME. 2019. The Role of the Gut Microbiome in Predicting Response to Diet and the Development of Precision Nutrition Models-Part I: Overview of Current Methods. Advances in nutrition (Bethesda, Md.) 10:953-978. DOI: 10.1093/advances/nmz022.

Hur KY, Lee M-S. 2015. Gut Microbiota and Metabolic Disorders. Diabetes \& metabolism journal 39:198-203. DOI: 10.4093/dmj.2015.39.3.198.

Jaacks LM, Vandevijvere S, Pan A, McGowan CJ, Wallace C, Imamura F, Mozaffarian D, Swinburn B, Ezzati M. 2019. The obesity transition: stages of the global epidemic. The Lancet Diabetes and Endocrinology 7:231-240. DOI: 10.1016/S2213-8587(19)30026-9.

Jain A, Li XH, Chen WN. 2018. Similarities and differences in gut microbiome composition correlate with dietary patterns of Indian and Chinese adults. AMB Express 8:104. DOI: 
719

720

721

722

723

724

725

726

727

728

729

730

731

732

733

734

735

736

737

738

739

740

741

742

743

744

745

746

747

748

749

10.1186/s13568-018-0632-1.

Jitnarin N, Kosulwat V, Rojroongwasinkul N, Boonpraderm A, Haddock CK, Poston WSC.

2011. Prevalence of overweight and obesity in Thai population: Results of the National Thai Food Consumption Survey. Eating and Weight Disorders 16:e242-e249. DOI: 10.1007/BF03327467.

Karlsson FH, Tremaroli V, Nookaew I, Bergström G, Behre CJ, Fagerberg B, Nielsen J, Bäckhed F. 2013. Gut metagenome in European women with normal, impaired and diabetic glucose control. Nature 498:99-103. DOI: 10.1038/nature12198.

Kasai C, Sugimoto K, Moritani I, Tanaka J, Oya Y, Inoue H, Tameda M, Shiraki K, Ito M, Takei Y, Takase K. 2015. Comparison of the gut microbiota composition between obese and nonobese individuals in a Japanese population, as analyzed by terminal restriction fragment length polymorphism and next-generation sequencing. BMC gastroenterology 15:100. DOI: 10.1186/s12876-015-0330-2.

Kisuse J, La-ongkham O, Nakphaichit M, Therdtatha P, Momoda R, Tanaka M, Fukuda S, Popluechai S, Kespechara K, Sonomoto K, Lee YK, Nitisinprasert S, Nakayama J. 2018a. Urban diets linked to gut microbiome and metabolome alterations in children: A comparative cross-sectional study in Thailand. Frontiers in Microbiology 9:1345. DOI: 10.3389/fmicb.2018.01345.

Kisuse J, La-Ongkham O, Nakphaichit M, Therdtatha P, Momoda R, Tanaka M, Fukuda S, Popluechai S, Kespechara K, Sonomoto K, Lee Y-K, Nitisinprasert S, Nakayama J. 2018 b. Urban Diets Linked to Gut Microbiome and Metabolome Alterations in Children: A Comparative Cross-Sectional Study in Thailand. Frontiers in microbiology 9:1345. DOI: 10.3389/fmicb.2018.01345.

Klindworth A, Pruesse E, Schweer T, Peplies J, Quast C, Horn M, Glöckner FO. 2013. Evaluation of general 16S ribosomal RNA gene PCR primers for classical and nextgeneration sequencing-based diversity studies. Nucleic acids research 41:e1-e1. DOI: 10.1093/nar/gks808.

Koliada A, Syzenko G, Moseiko V, Budovska L, Puchkov K, Perederiy V, Gavalko Y, Dorofeyev A, Romanenko M, Tkach S, Sineok L, Lushchak O, Vaiserman A. 2017. Association between body mass index and Firmicutes/Bacteroidetes ratio in an adult Ukrainian population. BMC Microbiology 17:120. DOI: 10.1186/s12866-017-1027-1. 
750 Kopp W. 2019. How western diet and lifestyle drive the pandemic of obesity and civilization

751

752

753

754

755

756

757

758

759

760

761

762

763

764

765

766

767

768

769

770

771

772

773

774

775

776

777

778

779

780

diseases. Diabetes, Metabolic Syndrome and Obesity: Targets and Therapy 12:2221-2236. DOI: $10.2147 /$ DMSO.S216791.

Kovatcheva-Datchary P, Nilsson A AR, Lee YS, De Vadder F, Arora T, Hallen A, Martens E, Bjorck I, Backhed F. 2015. Dietary fiber-induced improvement in glucose metabolism is associated with increased abundance of prevotella. Cell Metabolism 22:971-982. DOI: 10.1016/j.cmet.2015.10.001.

La-ongkham O, Nakphaichit M, Leelavatcharamas V, Keawsompong S, Nitisinprasert S. 2015. Distinct gut microbiota of healthy children from two different geographic regions of Thailand. Archives Microbiology 197:561-573. DOI: 10.1007/s00203-015-1089-0.

Lê Cao K-A, Martin PGP, Robert-Granié C, Besse P. 2009. Sparse canonical methods for biological data integration: application to a cross-platform study. BMC bioinformatics 10:34. DOI: 10.1186/1471-2105-10-34.

Lê Cao K-A, Rossouw D, Robert-Granié C, Besse P. 2008. A sparse PLS for variable selection when integrating omics data. Statistical applications in genetics and molecular biology 7:35. DOI: $10.2202 / 1544-6115.1390$.

Lê S, Josse J, Husson F. 2008. FactoMineR: An R package for multivariate analysis. Journal of Statistical Software 25:1-18.

Leung C, Rivera L, Furness JB, Angus PW. 2016. The role of the gut microbiota in NAFLD. Nature Reviews Gastroenterology and Hepatology 13:412-425. DOI: 10.1038/nrgastro.2016.85.

Lin S-W, Freedman ND, Shi J, Gail MH, Vogtmann E, Yu G, Klepac-Ceraj V, Paster BJ, Dye BA, Wang G-Q, Wei W-Q, Fan J-H, Qiao Y-L, Dawsey SM, Abnet CC. 2015. Betadiversity metrics of the upper digestive tract microbiome are associated with body mass index. Obesity (Silver Spring, Md.) 23:862-869. DOI: 10.1002/oby.21020.

Liu H, Wang J, He T, Becker S, Zhang G, Li D, Ma X. 2018. Butyrate: A Double-Edged Sword for Health? Advances in nutrition (Bethesda, Md.) 9:21-29. DOI:

10.1093/advances/nmx009.

Low WY. 2016. The Threat of Noncommunicable Diseases in South Asia. Asia-Pacific Journal of Public Health 28:4S-5S. DOI: 10.1177/1010539515623630.

Macpherson AJ, Harris NL. 2004. Interactions between commensal intestinal bacteria and the 
781

782

783

784

785

786

787

788

789

790

791

792

793

794

795

796

797

798

799

800

801

802

803

804

805

806

807

808

809

810

811

immune system. Nature Reviews Immunology 4:478-485. DOI: 10.1038/nri1373.

Magoč T, Salzberg SL. 2011. FLASH: fast length adjustment of short reads to improve genome assemblies. Bioinformatics (Oxford, England) 27:2957-2963. DOI: 10.1093/bioinformatics/btr507.

Manichanh C, Rigottier-Gois L, Bonnaud E, Gloux K, Pelletier E, Frangeul L, Nalin R, Jarrin C, Chardon P, Marteau P, Roca J, Dore J. 2006. Reduced diversity of faecal microbiota in Crohn's disease revealed by a metagenomic approach. Gut 55:205-211. DOI: 10.1136/gut.2005.073817.

Manzel A, Muller DN, Hafler DA, Erdman SE, Linker RA, Kleinewietfeld M. 2014. Role of "western diet" in inflammatory autoimmune diseases. Current Allergy and Asthma Reports 14:404. DOI: 10.1007/s11882-013-0404-6.

Mielke PWJ, Berry KJ. 2001. Permutation Methods: A Distance Function Approach. Springer Series in Statistics. Springer-Verlag New York.

Misra A, Khurana L. 2011. Obesity-related non-communicable diseases: South Asians vs White Caucasians. International Journal of Obesity 35:167-187. DOI: 10.1038/ijo.2010.135.

Mozaffarian D, Hao T, Rimm EB, Willett WC, Hu FB. 2011. Changes in diet and lifestyle and long-term weight gain in women and men. New England Journal of Medicine 364:23922404. DOI: 10.1056/NEJMoa1014296.

Murugesan S, Ulloa-Martínez M, Martínez-Rojano H, Galván-Rodríguez FM, Miranda-Brito C, Romano MC, Piña-Escobedo A, Pizano-Zárate ML, Hoyo-Vadillo C, García-Mena J. 2015. Study of the diversity and short-chain fatty acids production by the bacterial community in overweight and obese Mexican children. European journal of clinical microbiology \& infectious diseases : official publication of the European Society of Clinical Microbiology 34:1337-1346. DOI: 10.1007/s10096-015-2355-4.

Ndongo S, Lagier J-C, Fournier P-E, Raoult D, Khelaifia S. 2016. "Prevotellamassilia timonensis," a new bacterial species isolated from the human gut. New microbes and new infections 13:102-103. DOI: 10.1016/j.nmni.2016.06.014.

Nicholson JK, Holmes E, Kinross J, Burcelin R, Gibson G, Jia W, Pettersson S. 2012. Host-gut microbiota metabolic interactions. Science 336:1262-1267. DOI: 10.1126/science.1223813. Pampel FC, Denney JT, Krueger PM. 2012. Obesity, SES, and economic development: A test of the reversal hypothesis. Social Science and Medicine 74:1073-1081. DOI: 
812

813

814

815

816

817

818

819

820

821

822

823

824

825

826

827

828

829

830

831

832

833

834

835

836

837

838

839

840

841

842

10.1016/j.socscimed.2011.12.028.

Pareek S, Kurakawa T, Das B, Motooka D, Nakaya S, Rongsen-Chandola T, Goyal N, Kayama H, Dodd D, Okumura R, Maeda Y, Fujimoto K, Nii T, Ogawa T, Iida T, Bhandari N, Kida T, Nakamura S, Nair GB, Takeda K. 2019. Comparison of Japanese and Indian intestinal microbiota shows diet-dependent interaction between bacteria and fungi. npj Biofilms and Microbiomes 5:37. DOI: 10.1038/s41522-019-0110-9.

Peters BA, Shapiro JA, Church TR, Miller G, Trinh-Shevrin C, Yuen E, Friedlander C, Hayes RB, Ahn J. 2018. A taxonomic signature of obesity in a large study of American adults. Scientific Reports 8:9749. DOI: 10.1038/s41598-018-28126-1.

Png ME, Yoong J, Phan TP, Wee HL. 2016. Current and future economic burden of diabetes among working-age adults in Asia: conservative estimates for Singapore from 2010-2050. BMC Public Health 16:153. DOI: 10.1186/s12889-016-2827-1.

Provenzano LF, Stark S, Steenkiste A, Piraino B, Sevick MA. 2014. Dietary Sodium Intake in Type 2 Diabetes. Clinical diabetes : a publication of the American Diabetes Association 32:106-112. DOI: 10.2337/diaclin.32.3.106.

Qin J, Li Y, Cai Z, Li S, Zhu J, Zhang F, Liang S, Zhang W, Guan Y, Shen D, Peng Y, Zhang D, Jie Z, Wu W, Qin Y, Xue W, Li J, Han L, Lu D, Wu P, Dai Y, Sun X, Li Z, Tang A, Zhong S, Li X, Chen W, Xu R, Wang M, Feng Q, Gong M, Yu J, Zhang Y, Zhang M, Hansen T, Sanchez G, Raes J, Falony G, Okuda S, Almeida M, LeChatelier E, Renault P, Pons N, Batto J-M, Zhang Z, Chen H, Yang R, Zheng W, Li S, Yang H, Wang J, Ehrlich SD, Nielsen R, Pedersen O, Kristiansen K, Wang J. 2012. A metagenome-wide association study of gut microbiota in type 2 diabetes. Nature 490:55-60. DOI: 10.1038/nature11450.

Riaz Rajoka MS, Shi J, Mehwish HM, Zhu J, Li Q, Shao D, Huang Q, Yang H. 2017. Interaction between diet composition and gut microbiota and its impact on gastrointestinal tract health. Food Science and Human Wellness 6:121-130. DOI: https://doi.org/10.1016/j.fshw.2017.07.003.

Rinninella E, Cintoni M, Raoul P, Lopetuso LR, Scaldaferri F, Pulcini G, Miggiano GAD, Gasbarrini A, Mele MC. 2019. Food Components and Dietary Habits: Keys for a Healthy Gut Microbiota Composition. Nutrients 11:2393. DOI: 10.3390/nu11102393.

Rohart F, Gautier B, Singh A, Lê Cao K-A. 2017. mixOmics: An R package for 'omics feature selection and multiple data integration. PLOS Computational Biology 13:e1005752-. 
843 Ruengsomwong S, La-Ongkham O, Jiang J, Wannissorn B, Nakayama J, Nitisinprasert S. 2016. 844 Microbial Community of Healthy Thai Vegetarians and Non-Vegetarians, Their Core Gut 845 Microbiota, and Pathogen Risk. Journal of microbiology and biotechnology 26:1723-1735. 846 DOI: $10.4014 /$ jmb.1603.03057.

847 Sami W, Ansari T, Butt NS, Hamid MRA. 2017. Effect of diet on type 2 diabetes mellitus: A 848 review. International journal of health sciences 11:65-71.

849 Schwiertz A, Taras D, Schäfer K, Beijer S, Bos NA, Donus C, Hardt PD. 2010. Microbiota and 850 SCFA in lean and overweight healthy subjects. Obesity (Silver Spring, Md.) 18:190-195. 851 DOI: 10.1038/oby.2009.167.

852 Segata N, Izard J, Waldron L, Gevers D, Miropolsky L, Garrett WS, Huttenhower C. 2011. 853 Metagenomic biomarker discovery and explanation. Genome Biology 12:R60. DOI:

$854 \quad 10.1186 / \mathrm{gb}-2011-12-6-\mathrm{r} 60$.

855 Sekirov I, Russell SL, Caetano M Antunes L, Finlay BB. 2010. Gut microbiota in health and 856 disease. Physiological Reviews 90:859-904. DOI: 10.1152/physrev.00045.2009.

857 Senghor B, Sokhna C, Ruimy R, Lagier J-C. 2018. Gut microbiota diversity according to dietary 858 habits and geographical provenance. Human Microbiome Journal 7-8:1-9. DOI: 859 https://doi.org/10.1016/j.humic.2018.01.001.

860 Serino M, Nicolas S, Trabelsi M-S, Burcelin R, Blasco-Baque V. 2017. Young microbes for 861 adult obesity. Pediatric obesity 12:e28-e32. DOI: 10.1111/ijpo.12146.

862 Shen X, Miao J, Wan Q, Wang S, Li M, Pu F, Wang G, Qian W, Yu Q, Marotta F, He F. 2018. 863 Possible correlation between gut microbiota and immunity among healthy middle-aged and 864 elderly people in southwest China. Gut Pathogens 10:4. DOI: 10.1186/s13099-018-0231-3. 865 Swinburn BA, Sacks G, Hall KD, McPherson K, Finegood DT, Moodie ML, Gortmaker SL. 866 2011. The global obesity pandemic: Shaped by global drivers and local environments. The 867 Lancet 378:804-814. DOI: 10.1016/S0140-6736(11)60813-1.

868 Takagi T, Naito Y, Inoue R, Kashiwagi S, Uchiyama K, Mizushima K, Tsuchiya S, Dohi O, 869 Yoshida N, Kamada K, Ishikawa T, Handa O, Konishi H, Okuda K, Tsujimoto Y, Ohnogi 870 H, Itoh Y. 2019. Differences in gut microbiota associated with age, sex, and stool 871 consistency in healthy Japanese subjects. Journal of Gastroenterology 54:53-63. DOI: $872 \quad 10.1007 / \mathrm{s} 00535-018-1488-5$.

873 Tang WHW, Hazen SL. 2016. Dietary metabolism, gut microbiota and acute heart failure. Heart 
874

875

876

877

878

879

880

881

882

883

884

885

886

887

888

889

890

891

892

893

894

895

896

897

898

899

900

901

902

903

904

102:813-814. DOI: 10.1136/heartjnl-2016-309268.

Tremaroli V, Bäckhed F. 2012. Functional interactions between the gut microbiota and host metabolism. Nature 489:242-249. DOI: 10.1038/nature11552.

Tseng CH, Wu CY. 2019. The gut microbiome in obesity. Journal of the Formosan Medical Association 118 suppl:S3-S9. DOI: 10.1016/j.jfma.2018.07.009.

Turnbaugh PJ, Hamady M, Yatsunenko T, Cantarel BL, Duncan A, Ley RE, Sogin ML, Jones

WJ, Roe BA, Affourtit JP, Egholm M, Henrissat B, Heath AC, Knight R, Gordon JI. 2009. A core gut microbiome in obese and lean twins. Nature 457:480-484. DOI: 10.1038/nature 07540 .

Turnbaugh PJ, Ley RE, Mahowald MA, Magrini V, Mardis ER, Gordon JI. 2006. An obesityassociated gut microbiome with increased capacity for energy harvest. Nature 444:10271031. DOI: $10.1038 /$ nature05414.

De Vadder F, Kovatcheva-Datchary P, Goncalves D, Vinera J, Zitoun C, Duchampt A, Bäckhed F, Mithieux G. 2014. Microbiota-generated metabolites promote metabolic benefits via gutbrain neural circuits. Cell 156:84-96. DOI: 10.1016/j.cell.2013.12.016.

Valensi P, Picard S. 2011. Lipids, lipid-lowering therapy and diabetes complications. Diabetes \& metabolism 37:15-24. DOI: 10.1016/j.diabet.2010.10.001.

Vieira AT, Castelo PM, Ribeiro DA, Ferreira CM. 2017. Influence of oral and gut microbiota in the health of menopausal women. Frontiers in Microbiology 8:1884. DOI: 10.3389/fmicb.2017.01884.

Wang Y. 2001. Cross-national comparison of childhood obesity: The epidemic and the relationship between obesity and socioeconomic status. International Journal of Epidemiology 30:1129-1136. DOI: 10.1093/ije/30.5.1129.

Wang Q, Garrity GM, Tiedje JM, Cole JR. 2007. Naive Bayesian classifier for rapid assignment of rRNA sequences into the new bacterial taxonomy. Applied and environmental microbiology 73:5261-5267. DOI: 10.1128/AEM.00062-07.

Webber L, Kilpi F, Marsh T, Rtveladze K, Brown M, McPherson K. 2012. High rates of obesity and non-communicable diseases predicted across Latin America. PLoS ONE 7:e39589-

e39589. DOI: 10.1371/journal.pone.0039589.

Wickham H. 2009. ggplot2: Elegant Graphics for Data Analysis. Springer-Verlag, New York.

Wild S, Roglic G, Green A, Sicree R, King H. 2004. Global Prevalence of Diabetes: Estimates

Peer] reviewing PDF | (2020:03:46544:1:0:NEW 7 Jun 2020) 
905 for the year 2000 and projections for 2030. Diabetes Care 27:1047-1053. DOI:

$906 \quad 10.2337 /$ diacare.27.5.1047.

907 Wu GD, Chen J, Hoffmann C, Bittinger K, Chen Y-Y, Keilbaugh SA, Bewtra M, Knights D,

908 Walters WA, Knight R, Sinha R, Gilroy E, Gupta K, Baldassano R, Nessel L, Li H,

909 Bushman FD, Lewis JD. 2011. Linking long-term dietary patterns with gut microbial

910 enterotypes. Science (New York, N.Y.) 334:105-108. DOI: 10.1126/science.1208344.

911 Xanthos D. 2015. Country in Focus: Economic transition and non-communicable diseases in

912 Thailand. The Lancet Diabetes and Endocrinology 3:684-685. DOI: 10.1016/S2213-

913 8587(15)00294-6.

$914 \mathrm{Xu}$ Z, Knight R. 2015. Dietary effects on human gut microbiome diversity. The British journal of $915 \quad$ nutrition 113 Suppl:S1-S5. DOI: 10.1017/S0007114514004127.

$916 \mathrm{Xu} \mathrm{C}$, Zhu H, Qiu P. 2019. Aging progression of human gut microbiota. BMC Microbiology

917 19:236. DOI: 10.1186/s12866-019-1616-2.

918 Yannakoulia M. 2006. Eating behavior among type 2 diabetic patients: a poorly recognized

919 aspect in a poorly controlled disease. The review of diabetic studies : RDS 3:11-16. DOI:

$920 \quad 10.1900 /$ RDS.2006.3.11.

921 Yin YN, Yu QF, Fu N, Liu XW, Lu FG. 2010. Effects of four Bifidobacteria on obesity in high-

922 fat diet induced rats. World Journal of Gastroenterology 16:3394-3401. DOI:

$923 \quad 10.3748 /$ wjg.v16.i27.3394.

924 Yun Y, Kim H-N, Kim SE, Heo SG, Chang Y, Ryu S, Shin H, Kim H-L. 2017. Comparative

925 analysis of gut microbiota associated with body mass index in a large Korean cohort. BMC

926 microbiology 17:151. DOI: 10.1186/s12866-017-1052-0.

927 Zhang J, Guo Z, Xue Z, Sun Z, Zhang M, Wang L, Wang G, Wang F, Xu J, Cao H, Xu H, Lv Q,

928 Zhong Z, Chen Y, Qimuge S, Menghe B, Zheng Y, Zhao L, Chen W, Zhang H. 2015a. A

929 phylo-functional core of gut microbiota in healthy young Chinese cohorts across lifestyles,

930 geography and ethnicities. ISME Journal 9:1979-1990. DOI: 10.1038/ismej.2015.11.

931 Zhang YJ, Li S, Gan RY, Zhou T, Xu DP, Li H Bin. 2015b. Impacts of gut bacteria on human

932 health and diseases. International Journal of Molecular Sciences 16:7493-7519. DOI:

$933 \quad 10.3390 /$ ijms 16047493.

934 Zhang X, Shen D, Fang Z, Jie Z, Qiu X, Zhang C, Chen Y, Ji L. 2013. Human gut microbiota

935 changes reveal the progression of glucose intolerance. PloS one 8:e71108-e71108. DOI: 
$936 \quad$ 10.1371/journal.pone.0071108.

937

Peer] reviewing PDF | (2020:03:46544:1:0:NEW 7 Jun 2020) 


\section{Table 1 (on next page)}

Characteristics of the subjects that participated in this study.

One-way ANOVA test $(p<0.05)$ was used to compute the difference of mean for each characteristic across groups. Superscript letters indicate statistical comparison between the means of groups at a confidence interval of 0.95 . 


\begin{tabular}{|c|c|c|c|c|c|c|}
\hline Characteristic & Total $(n=30)$ & Lean $(n=8)$ & OV $(n=8)$ & OB $(n=7)$ & T2DM $(n=7)$ & $p$-value ${ }^{\mathrm{i}}$ \\
\hline Age (years) & $48.37 \pm 13.36$ & $49.13 \pm 7.66$ & $40.43 \pm 9.69^{\mathrm{e}}$ & $42.00 \pm 17.82^{\mathrm{g}}$ & $60.29 \pm 4.83^{\mathrm{e}, \mathrm{g}}$ & 0.0299 \\
\hline Gender (male/female) & $7 / 23$ & $1 / 7$ & $1 / 7$ & $4 / 3$ & $1 / 6$ & $0.2259^{\mathrm{j}}$ \\
\hline BMI $\left(\mathrm{kg} / \mathrm{m}^{2}\right)$ & $27.33 \pm 4.11$ & $23.70 \pm 1.30^{\mathrm{a}, \mathrm{b}}$ & $27.52 \pm 1.15^{\mathrm{b}, \mathrm{d}}$ & $33.28 \pm 2.15^{\mathrm{a}, \mathrm{d}, \mathrm{h}}$ & $25.55 \pm 3.25^{\mathrm{h}}$ & $p<0.000$ \\
\hline Weight (kg) & $69.18 \pm 15.06$ & $58.75 \pm 6.51^{\mathrm{a}}$ & $67.36 \pm 8.92^{\mathrm{d}}$ & $90.86 \pm 12.56^{\mathrm{a}, \mathrm{h}}$ & $62.14 \pm 5.77^{\mathrm{h}}$ & $p<0.000$ \\
\hline Height $(\mathrm{cm})$ & $158.53 \pm 9.10$ & $157.25 \pm 6.78$ & $156.14 \pm 9.22$ & $164.86 \pm 9.66$ & $156.43 \pm 8.45$ & 0.233 \\
\hline \multicolumn{7}{|l|}{ Blood pressure (BP) } \\
\hline $\begin{array}{l}\text { Systolic BP } \\
(\mathrm{mmHg})\end{array}$ & $138.23 \pm 15.84$ & $136.50 \pm 16.78$ & $135.29 \pm 10.05$ & $138.29 \pm 19.25$ & $139.71 \pm 13.67$ & 0.986 \\
\hline $\begin{array}{l}\text { Diastolic BP } \\
(\mathrm{mmHg})\end{array}$ & $87.50 \pm 9.14$ & $87.50 \pm 9.75$ & $89.71 \pm 11.50$ & $84.57 \pm 7.72$ & $87.00 \pm 5.81$ & 0.693 \\
\hline $\begin{array}{l}\text { Total cholesterol } \\
(\mathrm{mg} / \mathrm{dL})\end{array}$ & $206.90 \pm 38.21$ & $214.50 \pm 43.24$ & $225.57 \pm 40.44$ & $194.57 \pm 35.18$ & $192.57 \pm 21.74$ & 0.366 \\
\hline $\begin{array}{l}\text { LDL cholesterol } \\
(\mathrm{mg} / \mathrm{dL})\end{array}$ & $115.23 \pm 36.39$ & $112.63 \pm 36.42$ & $138.86 \pm 37.67$ & $114.00 \pm 32.19$ & $97.57 \pm 28.36$ & 0.296 \\
\hline $\begin{array}{l}\text { HDL cholesterol } \\
(\mathrm{mg} / \mathrm{dL})\end{array}$ & $60.63 \pm 17.08$ & $75.63 \pm 14.70^{f}$ & $60.14 \pm 14.53$ & $42.57 \pm 6.37^{\mathrm{f}}$ & $67.71 \pm 12.89$ & $p<0.000$ \\
\hline Triglyceride $(\mathrm{mg} / \mathrm{dL})$ & $154.37 \pm 79.61$ & $131.13 \pm 71.71$ & $132.14 \pm 41.92$ & $188.57 \pm 100.74$ & $165.71 \pm 78.87$ & 0.518 \\
\hline $\begin{array}{l}\text { Fasting glucose } \\
(\mathrm{mg} / \mathrm{dL})\end{array}$ & $111.60 \pm 34.60$ & $96.13 \pm 12.94^{\mathrm{c}}$ & $97.00 \pm 8.09^{\mathrm{e}}$ & $110.14 \pm 32.19$ & $146.29 \pm 50.37^{\mathrm{c}, \mathrm{e}}$ & 0.0142 \\
\hline
\end{tabular}

$2{ }^{\mathrm{a}}$ Lean $<\mathrm{OB}$, ${ }^{\mathrm{b}}$ Lean $<\mathrm{OV},{ }^{\mathrm{c}}$ Lean $<\mathrm{T} 2 \mathrm{DM},{ }^{\mathrm{d}} \mathrm{OV}<\mathrm{OB},{ }^{\mathrm{e}} \mathrm{OV}<\mathrm{T} 2 \mathrm{DM},{ }^{\mathrm{f}} \mathrm{OB}<$ Lean, ${ }^{\mathrm{g}} \mathrm{OB}<\mathrm{T} 2 \mathrm{DM},{ }^{\mathrm{h}} \mathrm{T} 2 \mathrm{DM}<\mathrm{OB}$. ${ }^{\mathrm{i}}$ one3 way ANOVA test. ${ }^{j}$ For gender, the statistical significance was assessed by post-hoc pairwise Fisher's exact test. 4 a,b,c,d,e,f,g,h Statistically significant differences were observed (Tukey-kramer post-hoc test, $p$ value adjusted $<0.05$ ). 


\section{Table 2 (on next page)}

sPLS analysis. The association of taxonomic composition at the level of genus with dietary consumption and blood profiles in different BMI groups and T2DM group. 


\begin{tabular}{|c|c|c|c|c|}
\hline $\begin{array}{l}\text { Bacterial } \\
\text { phyla }\end{array}$ & $\begin{array}{c}\text { Bacterial taxa (OTU } \\
\text { at genus level) }\end{array}$ & $\begin{array}{c}\text { Associated food } \\
\text { groups/blood profiles }\end{array}$ & Association & Study group (s) \\
\hline \multirow{4}{*}{ Firmicutes } & [Ruminococcus] & $\begin{array}{l}\text { Pea/ nut/ bean } \\
\text { Fish } \\
\text { Chicken } \\
\text { Brown rice } \\
\text { Green vegetable } \\
\text { Fruits } \\
\text { Fasting glucose } \\
\text { HDL cholesterol }\end{array}$ & $\begin{array}{l}\text { Negative }^{\mathrm{a}} \\
\text { Negative }^{\mathrm{a}} \\
\text { Negative }^{\mathrm{a}} \\
\text { Positive }^{\mathrm{b}} \\
\text { Negative }^{\mathrm{a}} \\
\text { Negative }^{\mathrm{a}} \\
\text { Negative }^{\mathrm{c}} \\
\text { Negative }^{\mathrm{c}}\end{array}$ & $\begin{array}{l}\text { OB } \\
\text { OB } \\
\text { OB } \\
\text { OV } \\
\text { OB } \\
\text { OB } \\
\text { OB } \\
\text { T2DM }\end{array}$ \\
\hline & Roseburia & $\begin{array}{l}\text { Pork } \\
\text { Chicken } \\
\text { Brown rice } \\
\text { Specified vegetables } \\
\text { Specified vegetables } \\
\text { Grain } \\
\text { Carbonate soft drink } \\
\text { Juice } \\
\text { Fasting glucose } \\
\text { HDL cholesterol } \\
\end{array}$ & $\begin{array}{l}\text { Negative }^{\mathrm{a}} \\
\text { Negative }^{\mathrm{a}} \\
\text { Positive }^{\mathrm{b}} \\
\text { Negative }^{\mathrm{a}} \\
\text { Positive }^{\mathrm{b}} \\
\text { Positive }^{\mathrm{b}} \\
\text { Negative }^{\mathrm{a}} \\
\text { Positive }^{\mathrm{a}} \\
\text { Positive }^{\mathrm{d}} \\
\text { Negative }^{\mathrm{c}}\end{array}$ & $\begin{array}{l}\text { OV } \\
\text { OV } \\
\text { L, OV } \\
\text { L } \\
\text { T2DM } \\
\text { T2DM } \\
\text { OB } \\
\text { T2DM } \\
\text { L, OV, T2DM } \\
\text { T2DM } \\
\end{array}$ \\
\hline & Faecalibacterium & $\begin{array}{l}\text { Pork } \\
\text { Brown rice } \\
\text { Specified vegetables } \\
\text { Grain } \\
\text { Juice } \\
\text { Fasting glucose }\end{array}$ & $\begin{array}{l}\text { Negative }^{\mathrm{a}} \\
\text { Positive }^{\mathrm{b}} \\
\text { Negative }^{\mathrm{a}} \\
\text { Negative }^{\mathrm{a}} \\
\text { Positive }^{\mathrm{b}} \\
\text { Positive }^{\mathrm{d}}\end{array}$ & $\begin{array}{l}\text { T2DM } \\
\text { L } \\
\text { L } \\
\text { OV } \\
\text { T2DM } \\
\text { L, OV, T2DM }\end{array}$ \\
\hline & Oscillospira & $\begin{array}{l}\text { HDL cholesterol } \\
\text { HDL cholesterol }\end{array}$ & $\begin{array}{l}\text { Negative }^{\mathrm{c}} \\
\text { Positive }^{\mathrm{d}} \\
\end{array}$ & $\begin{array}{l}\mathrm{OV} \\
\mathrm{OB}, \mathrm{T} 2 \mathrm{DM}\end{array}$ \\
\hline \multirow{3}{*}{ Bacteroidetes } & [Prevotella $]$ & $\begin{array}{l}\text { Pea/ nut/ bean } \\
\text { Beef } \\
\text { Sticky rice } \\
\text { Specified vegetables } \\
\text { Grain } \\
\text { Juice } \\
\text { Fasting glucose } \\
\text { Fasting glucose } \\
\end{array}$ & $\begin{array}{l}\text { Positive }^{\mathrm{b}} \\
\text { Positive }^{\mathrm{b}} \\
\text { Positive }^{\mathrm{b}} \\
\text { Positive }^{\mathrm{b}} \\
\text { Positive }^{\mathrm{b}} \\
\text { Positive }^{\mathrm{b}} \\
\text { Negative }^{\mathrm{c}} \\
\text { Positive }^{\mathrm{d}}\end{array}$ & $\begin{array}{l}\text { OB } \\
\text { OB } \\
\text { OB } \\
\text { L, OB } \\
\text { OB } \\
\text { OB } \\
\text { L, OV } \\
\text { OB } \\
\end{array}$ \\
\hline & Prevotella & $\begin{array}{l}\text { Pork } \\
\text { Sticky rice } \\
\text { Bread } \\
\text { Grain } \\
\text { Fermented fruits/vegetable } \\
\text { Green vegetable } \\
\text { Coffee } \\
\text { Alcohol } \\
\text { Carbonate soft drink } \\
\text { Fasting glucose } \\
\text { HDL cholesterol } \\
\end{array}$ & $\begin{array}{l}\text { Negative }^{\mathrm{a}} \\
\text { Positive }^{\mathrm{b}} \\
\text { Positive }^{\mathrm{b}} \\
\text { Negative }^{\mathrm{a}} \\
\text { Positive }^{\mathrm{b}} \\
\text { Negative }^{\mathrm{a}} \\
\text { Positive }^{\mathrm{b}} \\
\text { Negative }^{\mathrm{a}} \\
\text { Positive }^{\mathrm{b}} \\
\text { Positive }^{\mathrm{d}} \\
\text { Negative }^{\mathrm{c}}\end{array}$ & $\begin{array}{l}\text { T2DM } \\
\text { OB } \\
\text { T2DM } \\
\text { L } \\
\text { T2DM } \\
\text { T2DM } \\
\text { OV } \\
\text { OV } \\
\text { T2DM } \\
\text { L, OB } \\
\text { OV } \\
\end{array}$ \\
\hline & Bacteroides & $\begin{array}{l}\text { Brown rice } \\
\text { Bread } \\
\text { Grain } \\
\text { Specified vegetables } \\
\text { Fruits } \\
\text { Fasting glucose } \\
\text { HDL cholesterol }\end{array}$ & $\begin{array}{l}\text { Positive }^{\mathrm{b}} \\
\text { Negative }^{\mathrm{a}} \\
\text { Positive }^{\mathrm{b}} \\
\text { Positive }^{\mathrm{b}} \\
\text { Negative }^{\mathrm{a}} \\
\text { Negative }^{\mathrm{c}} \\
\text { Positive }^{\mathrm{d}}\end{array}$ & $\begin{array}{l}\text { OB } \\
\text { T2DM } \\
\text { L } \\
\text { L } \\
\text { T2DM } \\
\text { L } \\
\text { OV, OB, T2DM }\end{array}$ \\
\hline
\end{tabular}

1

\begin{tabular}{|c|l|l|l|l|}
\hline $\begin{array}{c}\text { Bacterial } \\
\text { phyla }\end{array}$ & $\begin{array}{c}\text { Bacterial taxa (OTU } \\
\text { at genus level) }\end{array}$ & $\begin{array}{c}\text { Associated food } \\
\text { groups/blood profiles }\end{array}$ & \multicolumn{1}{|c|}{ Association } & Study group (s) \\
\hline Fusobacteria & Fusobacterium & $\begin{array}{l}\text { Pork } \\
\text { Fish }\end{array}$ & $\begin{array}{l}\text { Positive } \\
\text { Positive }^{\mathrm{b}}\end{array}$ & $\begin{array}{l}\text { L, T2DM } \\
\text { L }\end{array}$
\end{tabular}




\begin{tabular}{|c|c|c|c|c|}
\hline & & $\begin{array}{l}\text { Dairy products } \\
\text { Beef } \\
\text { Rice vermicelli } \\
\text { Green vegetable } \\
\text { Fruits } \\
\text { Alcohol } \\
\text { Coffee } \\
\text { Carbonate soft drink } \\
\text { HDL cholesterol } \\
\text { HDL cholesterol } \\
\text { Fasting glucose } \\
\end{array}$ & $\begin{array}{l}\text { Positive }^{\mathrm{b}} \\
\text { Positive }^{\mathrm{b}} \\
\text { Positive }^{\mathrm{b}} \\
\text { Negative }^{\mathrm{a}} \\
\text { Negative }^{\mathrm{a}} \\
\text { Positive }^{\mathrm{b}} \\
\text { Negative }^{\mathrm{a}} \\
\text { Positive }^{\mathrm{b}} \\
\text { Positive }^{\mathrm{d}} \\
\text { Negative }^{\mathrm{c}} \\
\text { Negative }^{\mathrm{c}} \\
\end{array}$ & $\begin{array}{l}\text { T2DM } \\
\text { T2DM } \\
\text { T2DM } \\
\text { OB } \\
\text { OB } \\
\text { L } \\
\text { OV } \\
\text { OB } \\
\text { L, OV } \\
\text { OB, T2DM } \\
\text { OV }\end{array}$ \\
\hline \multirow[b]{2}{*}{ Proteobacteria } & Escherichia & $\begin{array}{l}\text { Brown rice } \\
\text { Juice } \\
\text { Fasting glucose } \\
\text { HDL cholesterol }\end{array}$ & $\begin{array}{l}\text { Positive }^{\mathrm{b}} \\
\text { Positive }^{\mathrm{b}} \\
\text { Positive }^{\mathrm{d}} \\
\text { Negative }^{\mathrm{c}}\end{array}$ & $\begin{array}{l}\text { OV } \\
\text { T2DM } \\
\text { OV, T2DM } \\
\text { T2DM }\end{array}$ \\
\hline & Sutterella & $\begin{array}{l}\text { Coffee } \\
\text { Juice } \\
\text { HDL cholesterol } \\
\text { HDL cholesterol } \\
\text { Fasting glucose } \\
\text { Fasting glucose }\end{array}$ & $\begin{array}{l}\text { Negative }^{\mathrm{a}} \\
\text { Negative }^{\mathrm{a}} \\
\text { Positive }^{\mathrm{d}} \\
\text { Negative }^{\mathrm{c}} \\
\text { Negative }^{\mathrm{c}} \\
\text { Positive }^{\mathrm{d}}\end{array}$ & $\begin{array}{l}\text { L } \\
\text { T2DM } \\
\text { L, T2DM } \\
\text { OB } \\
\text { OV, T2DM } \\
\text { OB }\end{array}$ \\
\hline
\end{tabular}

2 a Negative correlation: correlation coefficient $<-0.7$ for dietary consumption.

3 b Positive correlation: correlation coefficient $>0.7$ for dietary consumption.

$4{ }^{\mathrm{c}}$ Negative correlation: correlation coefficient $<-0.5$ for blood profiles.

5 dPositive correlation: correlation coefficient $>0.5$ for blood profiles. 


\section{Figure 1}

Venn diagram showing the number of microbial compositions according to OTU classification.

(A) Fecal microbiome OTUs in four groups (L, OV, OB, and T2DM). (B) OTU distribution in nondiabetic (L, OV, and OB) and diabetic subjects (T2DM).

A

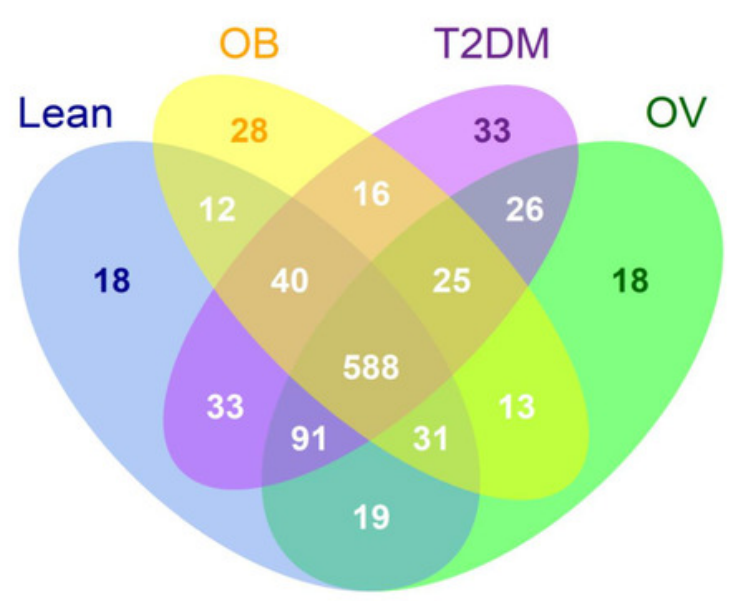

B

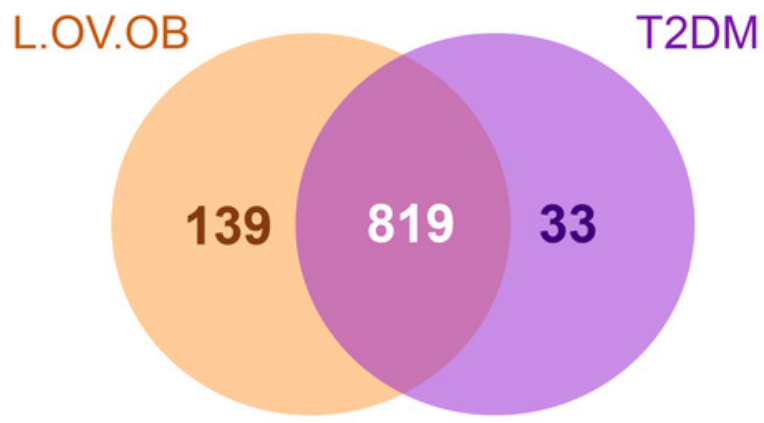




\section{Figure 2}

Boxplots of alpha diversity indices in each group (L, OV, OB, and T2DM).

The paired comparisons were determined using Wilcoxon rank-sum test adjusted for multiple testing with Benjamini-Hochberg method (asterisks indicate $q<0.05$ ).
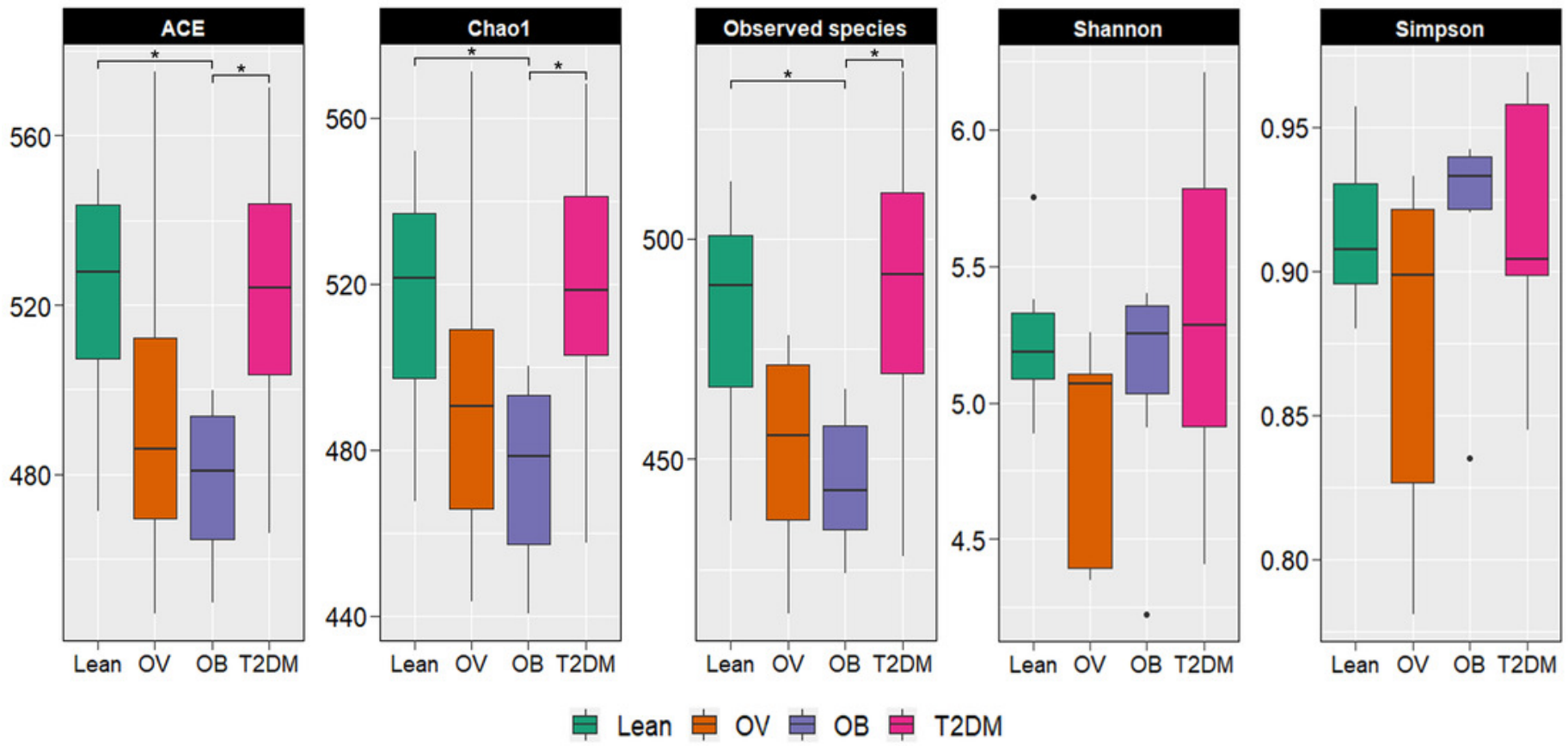

Lean 官 OV 官 OB 官 T2DM 


\section{Figure 3}

Gut microbial community abundance at the genus level.

(A) Bar plot of the relative abundance of top ten fecal gut microbiome at genus level presented in each subject. (B) Bar plot of the relative abundance of top ten fecal gut microbiome at genus level presented in each group. (C) Boxplot of relative abundance of Faecalibacterium across four groups. (D) Boxplot of relative abundance of [Prevotella] across four groups. Asterisks indicate $p<0.05$, Wilcoxon rank-sum test without Benjamini-Hochberg method.

A
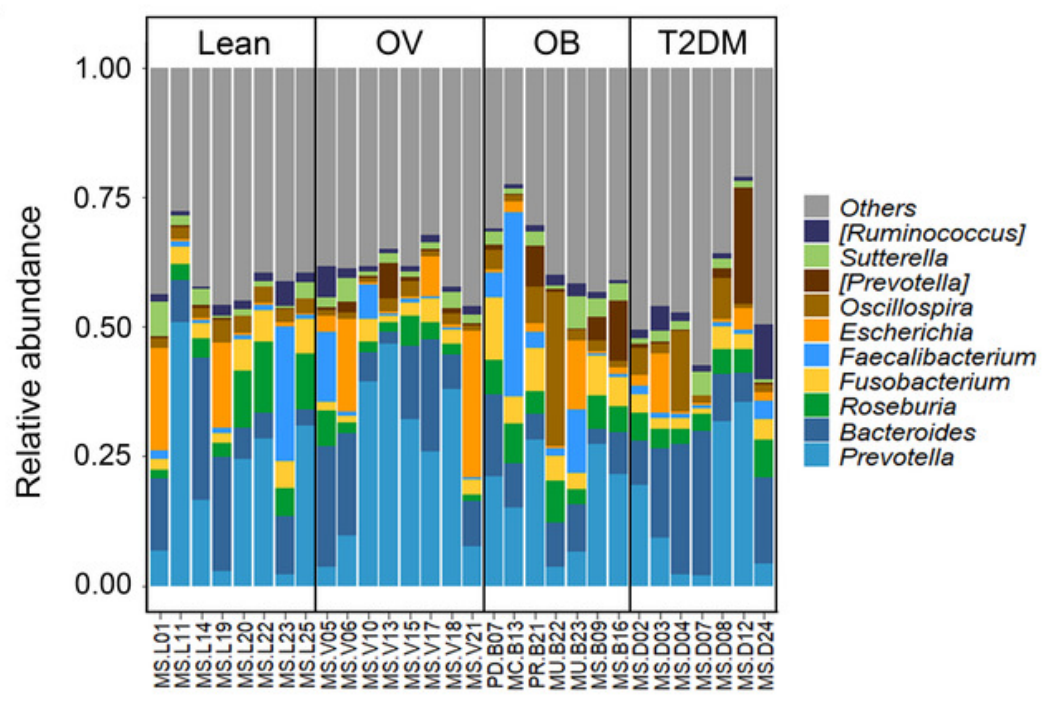

C

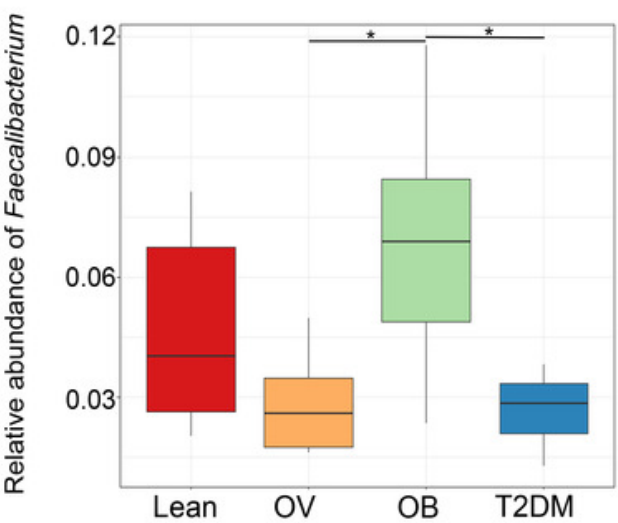

B

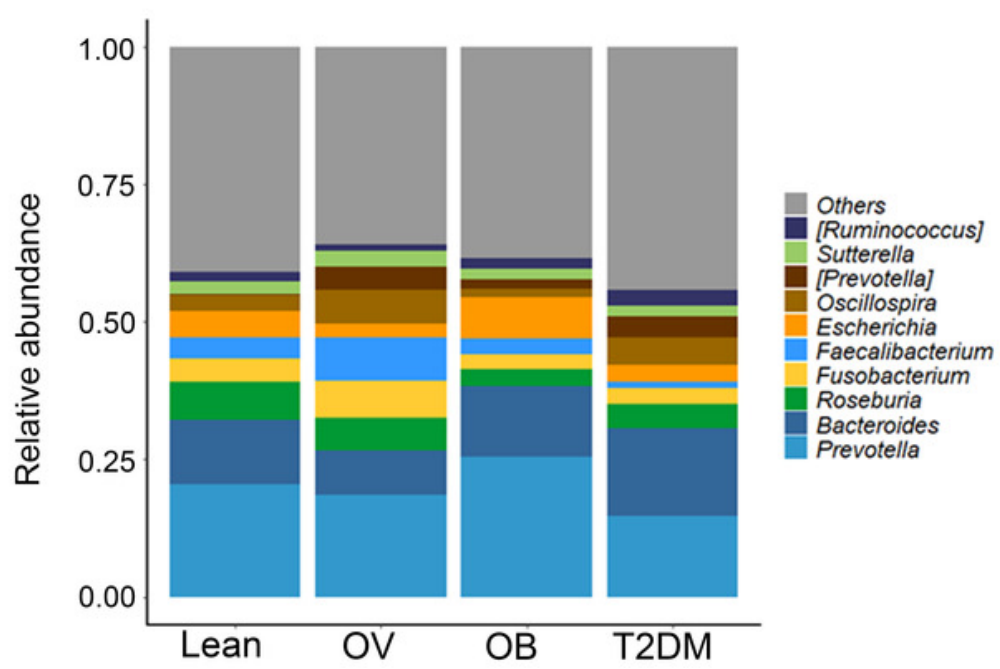

D

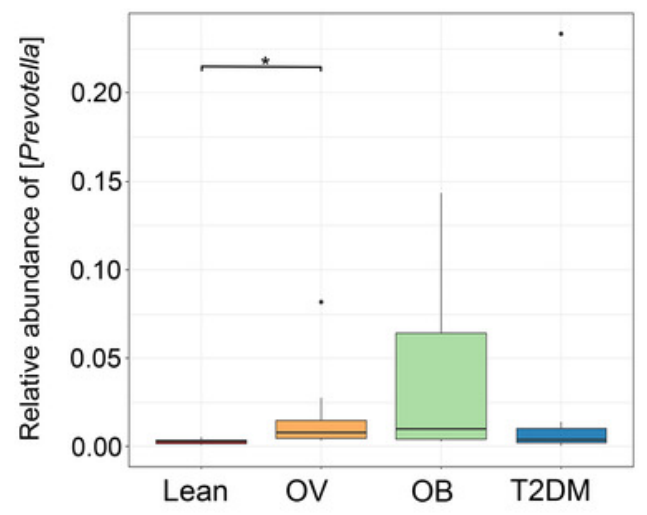




\section{Figure 4}

LEfSe analysis of fecal microbiota in BMI groups and T2DM group.

Histogram of LDA scores showing taxa with significant differences among groups (LEfSe bar at species level, $p<0.05$, LDA value $>4$ ). Species whose LDA scores (the effect size) are larger than 4 were presented as bars in different colors (blue, red, and green).

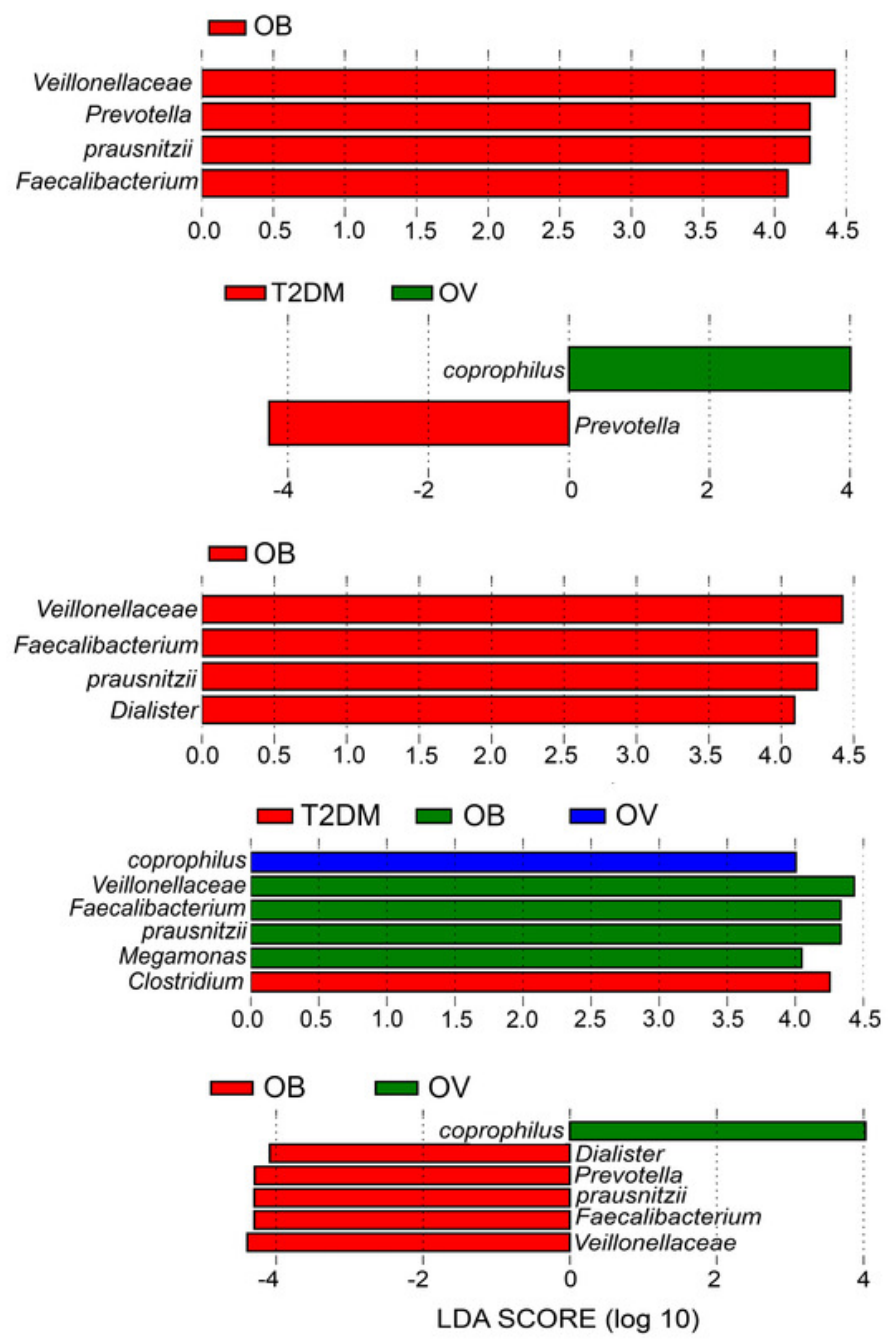

L-OV-OB comparisons

L-OV-T2DM comparisons

L-OB-T2DM comparisons

OV-OB-T2DM comparisons

L-OV-OB-T2DM comparisons 
Figure 5

Beta diversity analysis of the OTUs at phylum level.

(A) PCoA based on Weighted UniFrac distance. (B) PCoA based on Unweighted UniFrac

distance. Subjects from L, OV, OB and T2DM groups are labeled in red, green, black, and blue color, respectively.
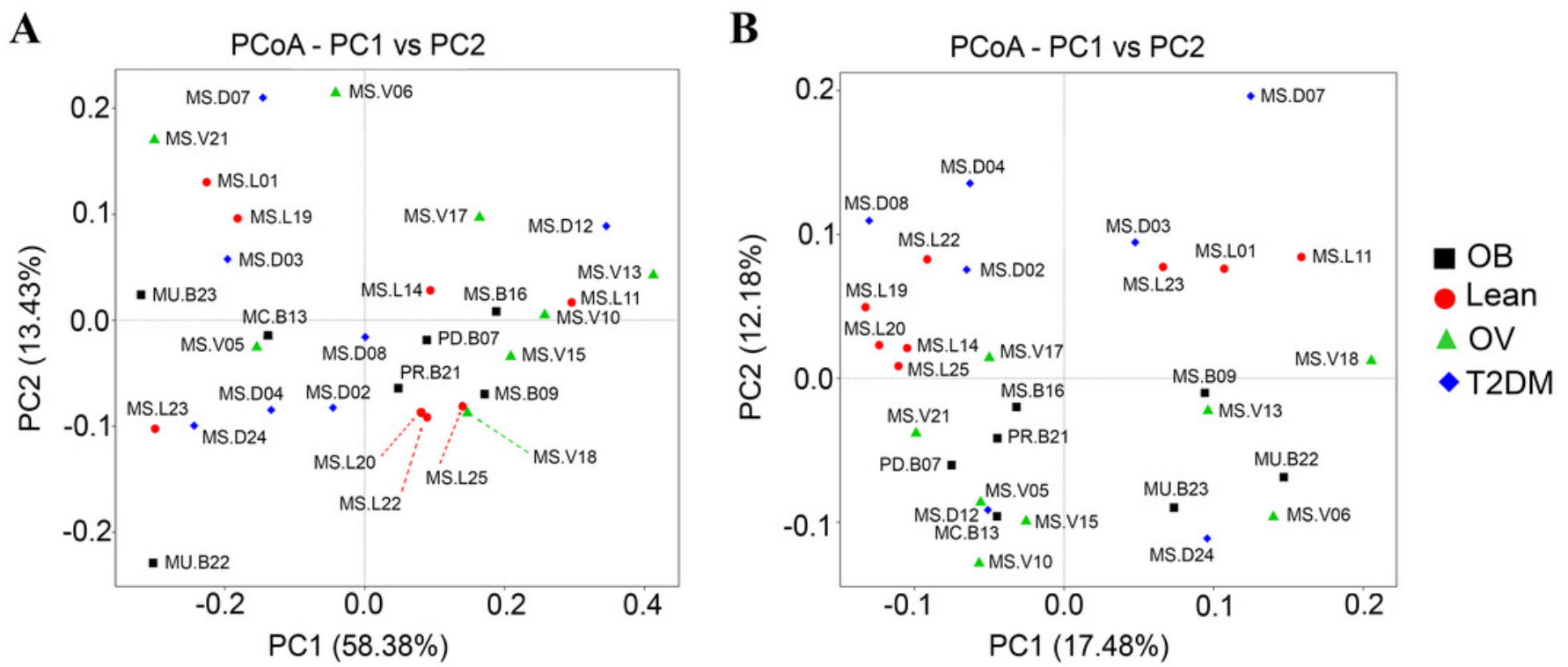


\section{Figure 6}

MFA analysis of dietary consumption, blood profiles, and fecal gut microbiota of subjects in different BMI groups and T2DM group.

The factor map presents the integration of dietary consumption, blood profiles (HDL cholesterol and fasting glucose level), and fecal gut microbiota (at genus level) of subjects in different BMI groups and T2DM group based on the MFA. The coordinates of the individuals are indicated by the $95 \%$ confidence ellipses including orange (L), blue (OV), green (OB), and purple (T2DM). 


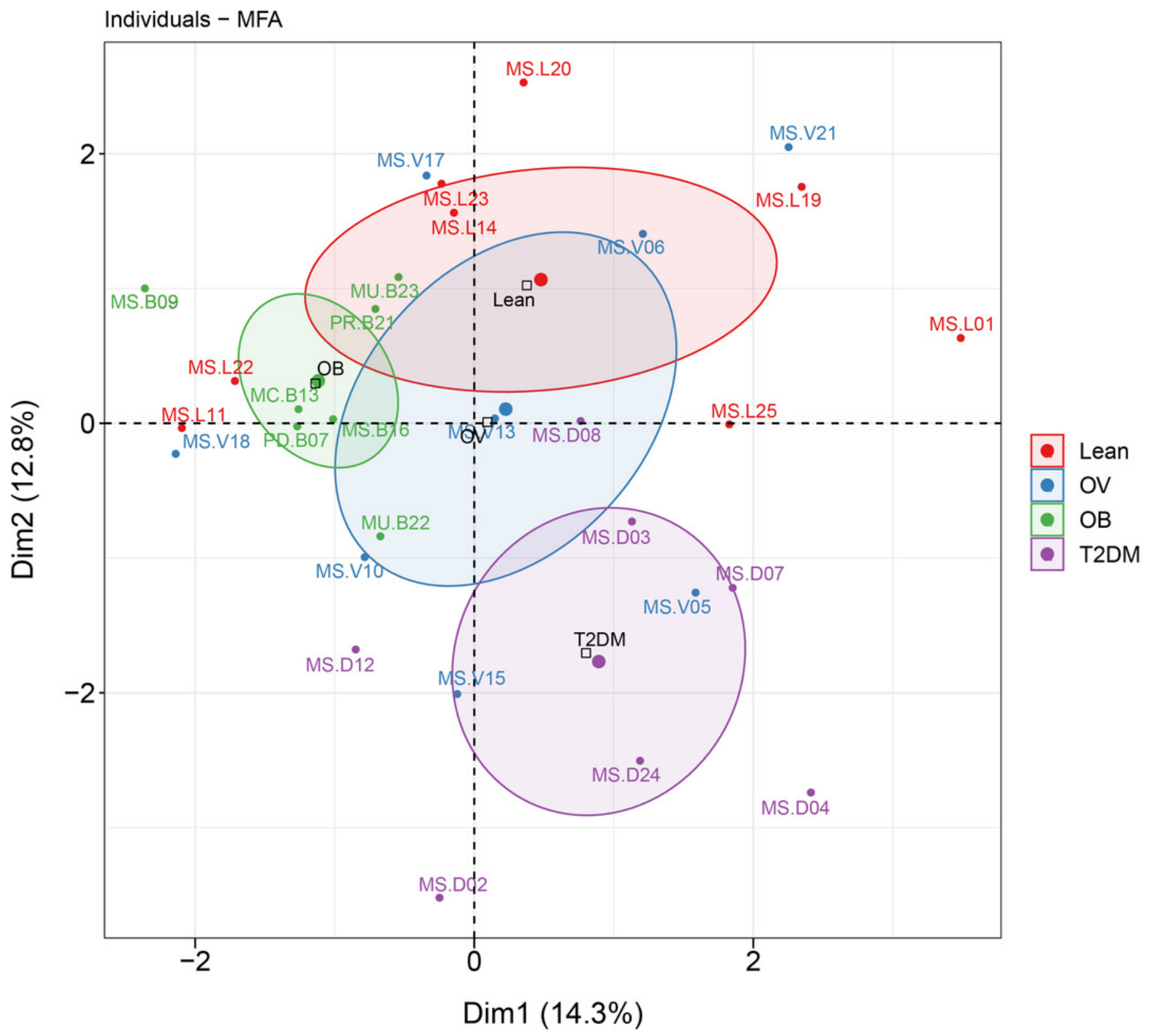

